Article

\title{
Large-Scale Green Supplier Selection Approach under a Q-Rung Interval-Valued Orthopair Fuzzy Environment
}

\author{
Limei Liu $^{1}$, Wenzhi Cao ${ }^{1}$, Biao Shi ${ }^{1, *}$ and Ming Tang ${ }^{2}$ \\ 1 Base of International Science and Technology Innovation and Cooperation on Big Data Technology and \\ management, Institute of Big Data and Internet Innovation, Hunan University of Technology and Business, \\ Changsha 410205, China \\ 2 College of Computer Science, Technological University Dublin, 999014 Dublin, Ireland \\ * Correspondence: $2698 @$ hnuc.edu.cn
}

Received: 12 July 2019; Accepted: 26 August 2019; Published: 29 August 2019

\begin{abstract}
As enterprises pay more and more attention to environmental issues, the green supply chain management (GSCM) mode has been extensively utilized to guarantee profit and sustainable development. Green supplier selection (GSS), which is a key segment of GSCM, has been investigated to put forward plenty of GSS approaches. At present, enterprises prefer to construct the large-scale teams of decision makers to obtain the more reasonable ranking results during GSS process. However, the existing methods pay little attention to the large-scale GSS procedure. To investigate the GSS issue with a large-scale group of decision makers, a new GSS approach under a q-rung interval-valued orthopair fuzzy environment is developed. The q-rung interval-valued orthopair fuzzy numbers are introduced to describe the evaluation information of green suppliers. Combined with a clustering approach and several clustering principles, the large-scale decision makers are divided into several subgroups. Next, the similarity measures between the evaluation matrices are computed to determine the weights of subgroups, and the collective evaluation information can be obtained using the q-rung interval-valued orthopair fuzzy aggregation operator. According to the weighted entropy measure, the weights of criteria are calculated; then, the q-rung interval-valued orthopair fuzzy multi-objective optimization on the basis of ratio analysis plus the full multiplicative form (q-RIVOF-MULTIMOORA) method is constructed to determine the best green supplier. At last, a practical GSS example is applied to show the feasibility of the proposed approach, and the sensitivity and comparative analyses indicate that for the large-scale GSS issues, the proposed approach can obtain the more robust and reasonable ranking results.
\end{abstract}

Keywords: large-scale green supplier selection; q-rung interval-valued orthopair fuzzy set; clustering method; q-RIVOF-MULTIMOORA method

\section{Introduction}

At present, the environmental protection issues have been widely concerned by global professions and trades, especially in the developing countries. Many laws and regulations have been issued by governments to restrict the enterprises' behaviors of damaging the environment; on the other hand, consumers are paying more and more attention to the environmental factor when they choose from different enterprises [1]. Under the pressures of government and consumers, most enterprises have changed their development mode from pursing profits blindly to synergistic development of benefits and environmental protection issues [2]. Consequently, the green supply chain management (GSCM) mode has been utilized to promote the environmental performance of enterprises during the management procedures of supply chains [3-6]. As a critical link of supply chains, green suppliers 
determine the environmental impact levels of supply chains and enterprises to a certain extent [7-9]; therefore, how to determine the best green supplier from several alternatives has been a hot topic, and a series of green supplier selection (GSS) approaches have been proposed by scholars [9]. On the basis of several potential green suppliers after the preliminary identification, this paper aims at developing a novel GSS approach with a large-scale group of decision makers to obtain the ranking result, which can provide guidance for enterprises in practice. On the other hand, the order allocation issue of different green suppliers also plays an important role during the GSCM process. Considering the multiple periods, multiple products, and other conditions, Moheb-Alizadeh and Handfield $[10,11]$ constructed the multi-objective programming models to solve the GSS and order allocation issues, simultaneously, which will be the future research direction of this study.

During the GSS process, enterprises or decision makers express their evaluation information of green suppliers concerning a collection of criteria; then, the ranking of green suppliers can be obtained through the information fusion. Accordingly, the GSS issues can be regarded as a kind of typical multiple criteria group decision making (GDM) problems [12-14]. Although many scholars have paid attention to investigate the GSS issue under fuzzy environment, the existing GSS approaches still present several limitations. (1) The fuzziness and uncertainty of evaluation information given by decision makers needs further characterization. (2) The involvement of large-scale decision makers during the evaluation process is rarely considered. (3) The robustness of ranking results needs to be further improved. Consequently, a novel GSS approach under a q-rung interval-valued orthopair fuzzy (q-RIVOF) environment is proposed in this paper to overcome the aforementioned limitations.

In practice, the decision makers' evaluation information of green suppliers is always imprecise and uncertain; thus, the tradition information form, i.e., crisp numbers, cannot deal with these situations effectively. To solve this problem, many scholars have introduced different forms of fuzzy sets to represent the evaluation information [15-17]. Among them, the q-rung orthopair fuzzy set (q-ROFS) [18] can describe the positive, negative, and indeterminacy membership levels of decision makers, simultaneously, which has been proven to be a powerful tool for evaluation process in practice [19-21]. Next, the interval numbers were utilized to extend the aforementioned three membership degrees to develop the q-rung interval-valued orthopair fuzzy set (q-RIVOFS) [22,23], whose capacity of expressing uncertainty is improved. Thus, this paper utilizes the q-RIVOFS to evaluate green suppliers during the evaluation process.

With the GSS issues attracting increasing attention, the ranking result obtained by a small-scale group of decision makers cannot already meet the high requirements of enterprises. Instead, enterprises hope to refer to more opinions; thus, the approach for GSS with large-scale decision makers (more than 20 decision makers [24]) is a valuable research topic. Nevertheless, to the best of our knowledge, few studies have focused on large-scale GSS issues. Furthermore, once the number of decision makers is relatively large, the extreme or non-consensus evaluation information may be inevitably expressed; hence, the accuracy of the ranking result will be affected negatively without managing the non-consensus evaluation information $[25,26]$. Therefore, we construct a clustering method under q-RIVOF environment to divide the large-scale group of decision makers into several subgroups, while the non-consensus evaluation information given by individual decision makers can be filtered out to be ignored; consequently, the accuracy of the ranking result obtained in this paper can be improved significantly.

Since the evaluation information of each subgroup is obtained by the proposed clustering method, the collective evaluation matrix can be obtained combined with the aggregation operators of q-rung interval-valued orthopair fuzzy numbers (q-RIVOFNs) [23]. Next, the important issue during the GSS process is how to rank the potential green suppliers according to their collective evaluation information; hence, many improved multiple criteria decision-making (MCDM) ranking approaches under a fuzzy environment were proposed to determine the best green supplier [9]. Brauers [27] investigated the robustness of different MCDM ranking methods and put forward that the robustness of MCDM ranking methods increases with the increase of its ranking patterns. Obviously, the ranking modes of most 
MCDM ranking approaches are single; the MOORA with the full multiplicative form (MULTIMOORA) ranking method is composed of three different ranking modes [28]; i.e., the ratio system, the reference point approach, and the full multiplicative form, which has been proven to be a powerful MCDM ranking tool with relatively strong robustness in practice [29-31]. In this study, the MULTIMOORA approach is applied into the q-RIVOF environment; thus, the q-rung interval-valued orthopair fuzzy MULTIMOORA (q-RIVOF-MULTIMOORA) ranking approach is developed to determine the best green supplier.

According to the aforementioned presentation, the purpose of this paper is to develop a new approach for solving the large-scale GSS issues, in which the uncertainty expression of evaluated information, the aggregation of large-scale decision makers' information, and the robustness of the ranking result have been improved. The main contributions of this study are concluded as in the following. (1) The q-RIVOFS is introduced to evaluate green suppliers, which can characterize the uncertainty and fuzziness of evaluation information and enlarge the evaluation freedom degree of decision makers, simultaneously. (2) A clustering approach based on the q-RIVOFS is developed to divide the large-scale decision makers into several subgroups, in which the evaluation information that deviates from group opinions can be ignored purposefully. (3) The MULTIMOORA approach is firstly applied to the q-RIVOF environment to construct the q-RIVOF-MULTIMOORA approach, in which a ranking of green suppliers with relatively strong robustness can be obtained. To achieve these improvements, the rest of this study can be arranged as below. Section 2 reviews the related literature systematically. Section 3 presents some important definitions of q-RIVOFS. A novel large-scale GSS approach is proposed in Section 4. A practical GSS example is implemented to investigate the performance of the proposed method in Section 5. Section 6 sums up several conclusions of this study.

\section{Literature Reviews}

\subsection{GSS Approaches}

During the past decades, due to the complexity of the GSS issues in practice, many fuzzy MCDM approaches have been introduced into the research field of improving the GSS process, including analytic hierarchy process (AHP), technique for order preference by similarity to ideal solution (TOPSIS), ViseKriterijumska Optimizacija I Kompromisno Resenje (VIKOR), and so on. For example, Deshmukh and Sunnapwar [32] utilized the triangular fuzzy numbers to replace the crisp numbers during the pairwise evaluation of green suppliers; then, the fuzzy AHP approach was proposed to determine the ranking. Dobos and Vörösmarty $[33,34]$ improved the environmental performance of suppliers according to the data envelopment analysis (DEA) model. Govindan et al. [35] improved the Simos procedure to calculate the criteria weights and applied the preference ranking organization method for enrichment evaluation (PROMETHEE) approach to rank green suppliers. Mati'c et al. [36] developed a hybrid GSS method based on the rough complex proportional assessment (COPRAS) method and the rough Dombi aggregator to evaluate green suppliers.

Besides, the weight vector of criteria also plays a critical role in determining the best green supplier. Many scholars utilized the existing weighting methods to compute the weights of criteria, which include the best-worst method (BWM), AHP, entropy weighting method, analytical network process (ANP), and so on; hence, many integrated GSS approach have been developed. For instance, combined with the BWM and alternative queuing method (AQM), Liu et al. [37] computed the weights of criteria and constructed the GSS approach under an interval-valued intuitionistic uncertain linguistic environment. Similarly, Yucesan et al. [38] utilized the BWM to calculate the criteria weights and developed the TOPSIS method based on an interval type-2 fuzzy set to rank green suppliers. In consideration of the subjective and objective elements, the AHP and entropy approaches were utilized to compute the comprehensive criteria weights; then, the entropy, elimination and choice expressing the reality III (ELECTRE III) approach was introduced to determine the best green supplier for the TFT-LCD industry [39]. In addition, Abdel-Baset et al. [40] applied triangular neutrosophic numbers to evaluate 
green suppliers and ranked them using an integrated MCDM method, which is composed of the ANP and VIKOR methods. Considering the interactions between the criteria, Hashemi et al. [41] calculated the weights of criteria by ANP method and determined the best green supplier using an improved grey relational analysis (GRA) approach. Similarly, combined with a synthetic method based on the decision-making trial and evaluation laboratory (DEMATEL) and ANP approaches, Kuo et al. [42] determined the criteria weights and solved the GSS issues with the VIKOR approach.

During the evaluation process of GSS, the evaluation behaviors of decision makers may be bounded rationally; hence, to deal with this situation, the TODIM (TOmada de Decisao Interativa e Multicritevio) method, which was developed according to prospect theory, was introduced to select green suppliers by many scholars [12,43]. Furthermore, to investigate the advantages of GSS approaches based on different MCDM methods, Banaeian et al. [15] and Rashidi and Cullinane [44] discussed the performance of different GSS approaches, which include approaches according to DEA, TOPSIS, VIKOR, and GRA methods.

\subsection{Q-RIVOFS}

In practice, the evaluation information is difficult to be characterized by crisp numbers accurately; decision makers may come from diverse professional backgrounds; they are likely to give the uncertain and fuzzy evaluation information. Therefore, since the fuzzy set theory was put forward by Zadeh [45], its generalized forms, i.e., triangular fuzzy set, type-2 fuzzy set, and interval type-2 fuzzy set, have been extensively utilized to evaluate green suppliers $[16,32,46]$. Nevertheless, the aforementioned generalized fuzzy sets only express the membership levels of decision makers, thus some practical evaluation information cannot be described by them; for instance, when one expert evaluates a viewpoint, he/she may think the correct probability is 0.7 , and the error probability is 0.2 . To overcome this limitation, the non-membership function was introduced to define the concept of an intuitionistic fuzzy set (IFS) [47]; later, the interval-valued intuitionistic fuzzy set (IVIFS) was proposed [48]. However, once the uncertainty of decision makers increases to a certain level, in which they want to expand the range of evaluation information; then, IFS cannot deal with this situation. For example, the expert above may express the correct and error probabilities as 0.7 and 0.4 , respectively. Therefore, Yager [49] relaxed the range of membership and non-membership levels to propose the Pythagorean fuzzy set (PFS); next, PFS was extended to develop the interval-valued Pythagorean fuzzy set (IVPFS) theory [50]. To further expand the range of evaluation information, Yager [18] put forward the q-ROFS based on IFS and PFS, which allows the expert above to give the correct and error probabilities as 0.8 and 0.7 , respectively. Thus, the space of acceptable orthopairs produced by IFS, PFS, and q-ROFS can be investigated as presented in Figure 1. According to the q-ROFS and interval numbers, Wang et al. [23] proposed the q-RIVOFS to construct a new GSS approach; unfortunately, the approach ignored the situations of the large-scale decision makers and the non-consensus evaluation information.
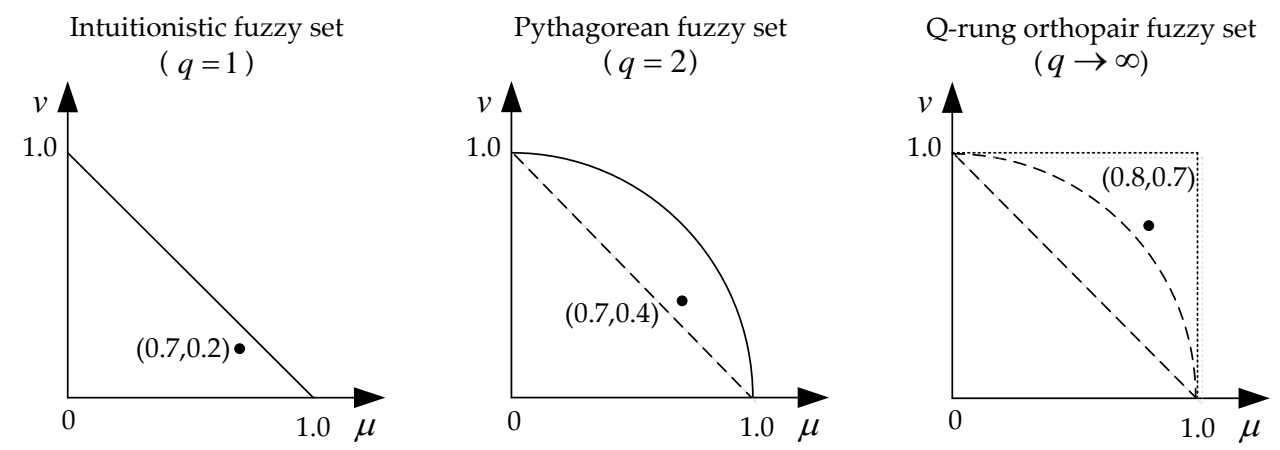

Figure 1. Space range of intuitionistic fuzzy set (IFS), Pythagorean fuzzy set (PFS), and q-rung orthopair fuzzy set (q-ROFS). 


\subsection{Large-Scale GDM Problems}

With the increasing importance of environmental issues in enterprises, enterprises pay more and more attention to determine the best green supplier during the GSCM process. Hence, enterprises will refer to more and more decision makers' evaluations of green suppliers. On the other hand, the non-consensus evaluation information may be given by individual decision makers, thus how to weaken its impact on the ranking result is an important issue. At present, many scholars have made efforts to propose large-scale GDM methods in different fields. For instance, $\mathrm{Xu}$ et al. [25] proposed an approach to manage the minority opinions and non-cooperative behaviors of decision makers and constructed an iterative-based consensus model to determine the best choice during the large-group emergency decision making procedure. Considering the multigranular linguistic scales utilized by the large-scale decision makers, Zhang et al. [51] normalized the different linguistic evaluation information to develop a novel large-scale GDM method. Palomares et al. [52] put forward an iterative consensus reaching algorithm to deal with the large-scale GDM issues, while the weights of decision makers with non-cooperative behaviors were penalized. Later, Liu et al. [53] utilized the consensus level to calculate the objective weights of participants during the large-scale GDM process. Wu and Xu [26] constructed a large-scale GDM approach under hesitant fuzzy environment, in which the clusters were allowed to change. To explore the effect of different classical consensus approaches during the large-scale GDM scenario, Labella et al. [54] made a comparative analysis between them to conclude several challenges of the classical consensus reaching processes. Unfortunately, little attention has been paid to the large-group GSS issues under q-RIVOF environment.

\section{Preliminaries}

In this section, several basic definitions of q-RIVOFS are recalled briefly. In addition, the Minkowski distance measure of q-RIVOFS is constructed, which will play an important role in this study.

\subsection{Q-RIVOFS}

According to IFS and PFS, Yager [18] developed the concept of q-ROFS to relax the decision makers' evaluation environment. Later, Joshi et al. [22], and Wang et al. [23] utilized the interval numbers to improve the q-ROFS, and the q-RIVOFS theory was proposed.

Definition 1 ([22,24]). Let $X$ be a non-empty and finite set, a $q$-RIVOFS $Q$ on $X$ is given as:

$$
Q=\left\{\left\langle x,\left(\widetilde{\mu}_{Q}(x), \widetilde{v}_{Q}(x)\right)\right\rangle \mid x \in X\right\},
$$

where the interval numbers $\widetilde{\mu}_{Q}(x)=\left[\mu_{Q}^{-}(x), \mu_{Q}^{+}(x)\right] \subset[0,1]$ and $\widetilde{v}_{Q}(x)=\left[v_{Q}^{-}(x), v_{Q}^{+}(x)\right] \subset[0,1]$ indicate the positive and negative membership levels of the element $x \in X$ to $Q$, respectively, which meet the condition of $0 \leq\left(\mu_{Q}^{+}(x)\right)^{q}+\left(v_{Q}^{+}(x)\right)^{q} \leq 1, q \geq 1$. In addition, the interval number $\widetilde{\pi}_{Q}(x)=\left[\pi_{Q}^{-}(x), \pi_{Q}^{+}(x)\right]=$ $\left[\sqrt[q]{1-\left(\left(\mu_{Q}^{+}(x)\right)^{q}+\left(v_{Q}^{+}(x)\right)^{q}\right)}, \sqrt[q]{1-\left(\left(\mu_{Q}^{-}(x)\right)^{q}+\left(v_{Q}^{-}(x)\right)^{q}\right)}\right]$ represents the indeterminacy membership level of the element $x \in X$ to $Q$. For the convenience of research, we call $a=\left(\left[\mu^{-}, \mu^{+}\right],\left[v^{-}, v^{+}\right]\right)$a q-RIVOFN.

To better apply the q-RIVOFS theory to practical decision-making issues, Wang et al. [23] investigated the operations and comparison method of different q-RIVOFNs in detail.

Definition 2 ([23]). Let $a=\left(\left[\mu^{-}, \mu^{+}\right],\left[v^{-}, v^{+}\right]\right), a_{1}=\left(\left[\mu_{1}^{-}, \mu_{1}^{+}\right],\left[v_{1}^{-}, v_{1}^{+}\right]\right)$, and $a_{2}=\left(\left[\mu_{2}^{-}, \mu_{2}^{+}\right],\left[v_{2}^{-}, v_{2}^{+}\right]\right)$ be three $q$-RIVOFNs, $\lambda>0, a^{c}$ is the complementary $q$-RIVOFN of $a$; then

$$
a^{c}=\left(\left[v^{-}, v^{+}\right],\left[\mu^{-}, \mu^{+}\right]\right) ;
$$




$$
\begin{gathered}
a_{1} \oplus a_{2}=\left(\left[\sqrt[q]{\left(\mu_{1}^{-}\right)^{q}+\left(\mu_{2}^{-}\right)^{q}-\left(\mu_{1}^{-}\right)^{q}\left(\mu_{2}^{-}\right)^{q}}, \sqrt[q]{\left(\mu_{1}^{+}\right)^{q}+\left(\mu_{2}^{+}\right)^{q}-\left(\mu_{1}^{+}\right)^{q}\left(\mu_{2}^{+}\right)^{q}}\right],\left[v_{1}^{-} v_{2}^{-}, v_{1}^{-} v_{2}^{-}\right]\right) ; \\
a_{1} \otimes a_{2}=\left(\left[\mu_{1}^{-} v_{2}^{-}, \mu_{1}^{-} \mu_{2}^{-}\right],\left[\sqrt[q]{\left(v_{1}^{-}\right)^{q}+\left(v_{2}^{-}\right)^{q}-\left(v_{1}^{-}\right)^{q}\left(v_{2}^{-}\right)^{q}}, \sqrt[q]{\left(v_{1}^{+}\right)^{q}+\left(v_{2}^{+}\right)^{q}-\left(v_{1}^{+}\right)^{q}\left(v_{2}^{+}\right)^{q}}\right]\right) ; \\
\lambda a=\left(\left[\sqrt[q]{1-\left(1-\left(\mu^{-}\right)^{q}\right)^{\lambda}}, \sqrt[q]{1-\left(1-\left(\mu^{+}\right)^{q}\right)^{\lambda}}\right],\left[\left(v^{-}\right)^{\lambda},\left(v^{+}\right)^{\lambda}\right]\right) ; \\
a^{\lambda}=\left(\left[\left(\mu^{-}\right)^{\lambda},\left(\mu^{+}\right)^{\lambda}\right],\left[\sqrt[q]{1-\left(1-\left(v^{-}\right)^{q}\right)^{\lambda}}, \sqrt[q]{1-\left(1-\left(v^{+}\right)^{q}\right)^{\lambda}}\right]\right) .
\end{gathered}
$$

Definition 3 ([23]). Let $a=\left(\left[\mu^{-}, \mu^{+}\right],\left[v^{-}, v^{+}\right]\right)$be a $q$-RIVOFN, then its score and accuracy functions can be defined, respectively, as follows:

$$
\begin{gathered}
s(a)=\frac{1}{4}\left[\left(1+\left(\mu^{-}\right)^{q}-\left(v^{-}\right)^{q}\right)+\left(1+\left(\mu^{+}\right)^{q}-\left(v^{+}\right)^{q}\right)\right] ; \\
h(a)=\frac{1}{2}\left(\left(\mu^{-}\right)^{q}+\left(v^{-}\right)^{q}+\left(\mu^{+}\right)^{q}+\left(v^{+}\right)^{q}\right) .
\end{gathered}
$$

Definition 4 ([23]). Let $a_{1}=\left(\left[\mu_{1}^{-}, \mu_{1}^{+}\right],\left[v_{1}^{-}, v_{1}^{+}\right]\right)$and $a_{2}=\left(\left[\mu_{2}^{-}, \mu_{2}^{+}\right],\left[v_{2}^{-}, v_{2}^{+}\right]\right)$be two q-RIVOFNs, then

(1) If $s\left(a_{1}\right)<s\left(a_{2}\right)$, then $a_{1}<a_{2}$;

(2) If $s\left(a_{1}\right)=s\left(a_{2}\right)$, then:

a. if $h\left(a_{1}\right)<h\left(a_{2}\right)$, then $a_{1}<a_{2}$;

b. if $h\left(a_{1}\right)=h\left(a_{2}\right)$, then $a_{1}=a_{2}$.

\subsection{Distance Measure of $q$-RIVOFS}

Inspired by the literature $[55,56]$, we can put forward the Minkowski distance measure between different q-RIVOFNs, and several particular distance measures reduced from the Minkowski distance are presented.

Definition 5. Let $a_{1}=\left(\left[\mu_{1}^{-}, \mu_{1}^{+}\right],\left[v_{1}^{-}, v_{1}^{+}\right]\right)$and $a_{2}=\left(\left[\mu_{2}^{-}, \mu_{2}^{+}\right],\left[v_{2}^{-}, v_{2}^{+}\right]\right)$be two $q$-RIVOFNs, afterwards the Minkowski distance between them is given by:

$$
d_{M}\left(a_{1}, a_{2}\right)=\left(\frac{1}{4}\left|\mu_{1}^{-}-\mu_{2}^{-}\right|^{p}+\frac{1}{4}\left|\mu_{1}^{+}-\mu_{2}^{+}\right|^{p}+\frac{1}{4}\left|v_{1}^{-}-v_{2}^{-}\right|^{p}+\frac{1}{4}\left|v_{1}^{+}-v_{2}^{+}\right|^{p}\right)^{1 / p}, p \geq 1
$$

When $p=1$, the Minkowski distance between $a_{1}$ and $a_{2}$ can be reduced to the Hamming distance as

$$
d_{H}\left(a_{1}, a_{2}\right)=\frac{1}{4}\left(\left|\mu_{1}^{-}-\mu_{2}^{-}\right|+\left|\mu_{1}^{+}-\mu_{2}^{+}\right|+\left|v_{1}^{-}-v_{2}^{-}\right|+\left|v_{1}^{+}-v_{2}^{+}\right|\right)
$$

When $p=2$, the Minkowski distance between $a_{1}$ and $a_{2}$ can be reduced to the Euclidean distance as

$$
d_{E}\left(a_{1}, a_{2}\right)=\left(\frac{1}{4}\left|\mu_{1}^{-}-\mu_{2}^{-}\right|^{2}+\frac{1}{4}\left|\mu_{1}^{+}-\mu_{2}^{+}\right|^{2}+\frac{1}{4}\left|v_{1}^{-}-v_{2}^{-}\right|^{2}+\frac{1}{4}\left|v_{1}^{+}-v_{2}^{+}\right|^{2}\right)^{1 / 2} .
$$


When $p \rightarrow+\infty$, the Minkowski distance between $a_{1}$ and $a_{2}$ can be reduced to the Chebyshev distance as

$$
d_{\infty}\left(a_{1}, a_{2}\right)=\max \left\{\left|\mu_{1}^{-}-\mu_{2}^{-}\right|,\left|\mu_{1}^{+}-\mu_{2}^{+}\right|,\left|v_{1}^{-}-v_{2}^{-}\right|,\left|v_{1}^{+}-v_{2}^{+}\right|\right\} .
$$

It can be easily proven that the Minkowski distance measure between different q-RIVOFNs above has the following properties.

Theorem 1. Let $d_{M}\left(a_{1}, a_{2}\right)$ be the Minkowski distance between two q-RIVOFNs $a_{1}=\left(\left[\mu_{1}^{-}, \mu_{1}^{+}\right],\left[v_{1}^{-}, v_{1}^{+}\right]\right)$ and; we have then

(1) $0 \leq d_{M}\left(a_{1}, a_{2}\right) \leq 1$;

(2) $d_{M}\left(a_{1}, a_{2}\right)=0$, if and only if $a_{1}=a_{2}$;

(3) $d_{M}\left(a_{1}, a_{2}\right)=d_{M}\left(a_{2}, a_{1}\right)$.

\subsection{The Q-rung Interval-Valued Orthopair Fuzzy Weighted Aggregation Operators}

The aggregation operator is a key tool to fuse evaluation information; thus, we introduce the q-RIVOFWA and q-RIVOFWG operators [23] to aggregate the q-RIVOFNs, which will be utilized to construct the MULTIMOORA approach under q-RIVOF environment.

Definition 6 ([23]). Let $a_{i}=\left(\left[\mu_{i}^{-}, \mu_{i}^{+}\right],\left[v_{i}^{-}, v_{i}^{+}\right]\right)(i=1,2, \ldots, n)$ be a series of $q$-RIVOFNs; the $q$-RIVOFWA operator is a mapping $Q^{n} \rightarrow Q$ as

$$
q-\operatorname{RIVOFWA}\left(a_{1}, a_{2}, \ldots, a_{n}\right)=\underset{i=1}{\oplus} w_{i} a_{i}
$$

where $w=\left(w_{1}, w_{2}, \ldots, w_{n}\right)^{T}$ is the weight vector of $q$-RIVOFNs, which satisfies the conditions of $0 \leq w_{i} \leq 1$ and $\sum_{i=1}^{n} w_{i}=1$. Combined with the operational laws of $q$-RIVOFNs, the aggregated value by using $q$-RIVOFWA operator is also a $q$-RIVOFN as

$$
q-\operatorname{RIVOFWA}\left(a_{1}, a_{2}, \ldots, a_{n}\right)=\left(\left[\sqrt[q]{1-\prod_{i=1}^{n}\left(1-\mu_{i}^{-}\right)^{w_{i}}}, \sqrt[q]{1-\prod_{i=1}^{n}\left(1-\mu_{i}^{+}\right)^{w_{i}}}\right],\left[\prod_{i=1}^{n}\left(v_{i}^{-}\right)^{w_{i}}, \prod_{i=1}^{n}\left(v_{i}^{+}\right)^{w_{i}}\right]\right)
$$

Definition 7. ([23]). Let $a_{i}=\left(\left[\mu_{i}^{-}, \mu_{i}^{+}\right],\left[v_{i}^{-}, v_{i}^{+}\right]\right)(i=1,2, \ldots, n)$ be a series of $q$-RIVOFNs; the $q$-RIVOFWG operator is a mapping $Q^{n} \rightarrow Q$ as

$$
q-\operatorname{RIVOFWG}\left(a_{1}, a_{2}, \ldots, a_{n}\right)=\stackrel{n}{\otimes} a_{i}^{i w_{i}},
$$

where $w=\left(w_{1}, w_{2}, \ldots, w_{n}\right)^{T}$ is the weight vector of $q$-RIVOFNs, which satisfies the conditions of $0 \leq w_{i} \leq 1$ and $\sum_{i=1}^{n} w_{i}=1$. Combined with the operational laws of $q$-RIVOFNs, the aggregated value by using q-RIVOFWG operator is also a q-RIVOFN as

$$
q-\operatorname{RIVOFWG}\left(a_{1}, a_{2}, \ldots, a_{n}\right)=\left(\left[\prod_{i=1}^{n}\left(\mu_{i}^{-}\right)^{w_{i}}, \prod_{i=1}^{n}\left(\mu_{i}^{+}\right)^{w_{i}}\right],\left[\sqrt[q]{1-\prod_{i=1}^{n}\left(1-v_{i}^{-}\right)^{w_{i}}}, \sqrt[q]{1-\prod_{i=1}^{n}\left(1-v_{i}^{+}\right)^{w_{i}}}\right]\right)
$$

\section{The Proposed Large-Scale GSS Approach}

With the increasing attention on the GSS issues, the scale of decision makers involved the decision-making process is also growing significantly in practice. In general, a GDM problem, in which the number of decision makers exceeds 20, can constitute a large-scale GDM issue [57,58]. Hence, this paper aims to develop a novel approach for the large-scale GSS, which can be implemented by 
four processes; namely, the clustering process of large-scale decision makers, aggregation process of individual evaluation information, determination process of the criteria weights, and ranking process using the q-RIVOF-MULTIMOORA method. The visible flow diagram of the proposed large-scale GSS approach is shown in Figure 2.

For a large-scale GSS issue, suppose that a large-scale group of decision makers $D M_{k}(k=1,2, \ldots, l ; l \geq 20)$ evaluates a collection of green suppliers $G_{i}(i=1,2, \ldots, m)$ concerning several criteria $C_{j}(j=1,2, \ldots, n)$ by using the linguistic terms. Consequently, the q-RIVOF evaluation matrices of decision makers $F^{k}=\left(\bar{a}_{i j}^{k}\right)_{m \times n}$ can be obtained by transforming the linguistic terms into their corresponding q-RIVOFNs, where $\bar{a}_{i j}^{k}=\left(\left[\bar{\mu}_{i j}^{k-}, \bar{\mu}_{i j}^{k+}\right],\left[\bar{v}_{i j}^{k-}, \bar{v}_{i j}^{k+}\right]\right)$.

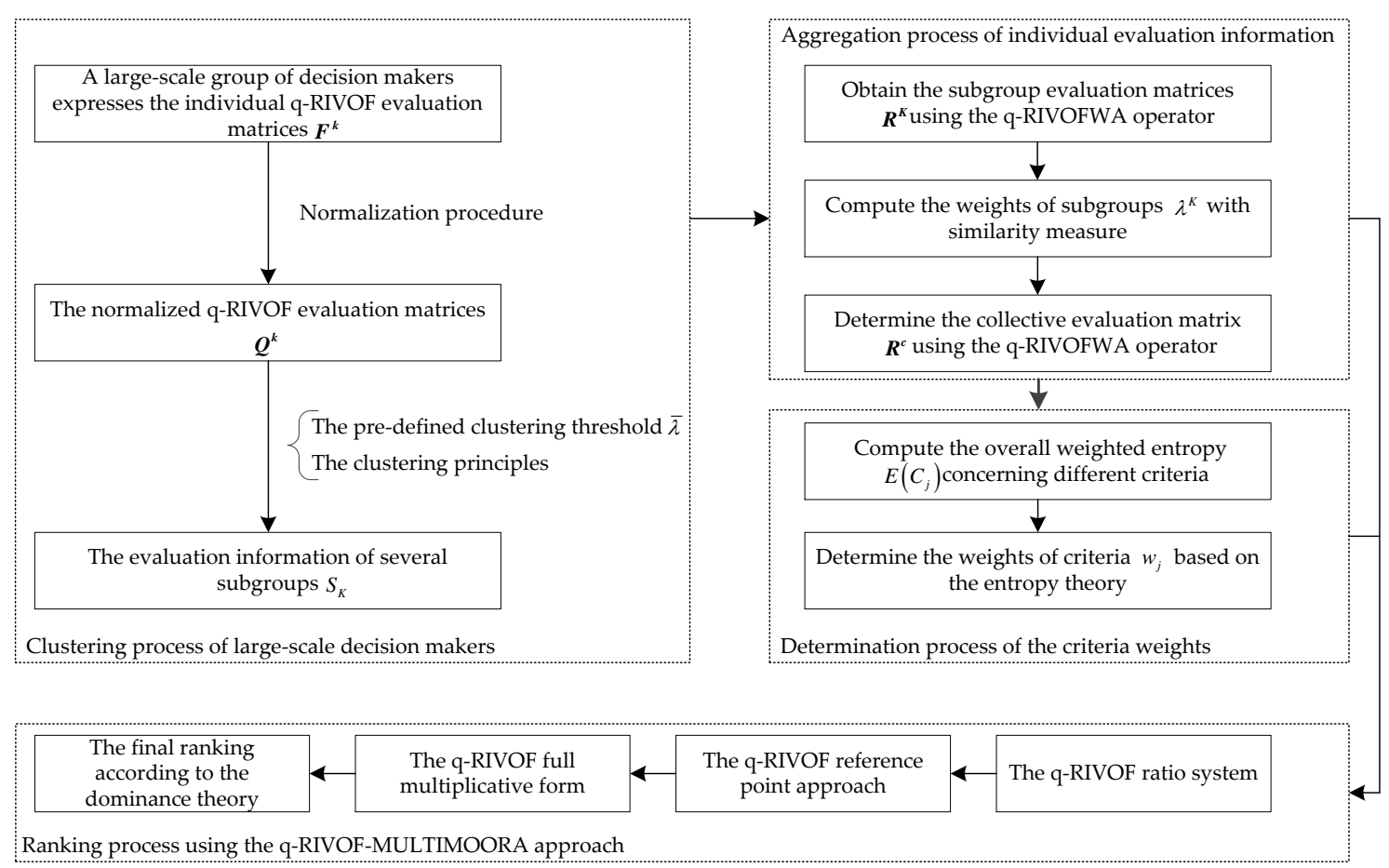

Figure 2. Flowchart of the proposed large-scale green supplier selection (GSS) approach.

\subsection{Clustering Process of Large-Scale Decision Makers}

During the GDM process, the consensus level between decision makers is a critical factor to measure the rationality of the ranking result, especially when large-scale decision makers participate in the evaluation mission. In practice, decision makers may vary, with diverse backgrounds and experiences, thus, the evaluation information that deviates from group opinions may be expressed by individual decision makers. Hence, we can introduce the clustering approach to determine the ranking result accepted by decision makers or enterprise. After the clustering analysis, several subgroups can be derived from the numerous evaluation information, in which the decision makers have similar opinions on the potential green suppliers. Subsequently, the evaluation information of subgroups can be utilized to complete the subsequent decision making, and the clustering analysis makes the following processes easier to handle, simultaneously.

Many clustering algorithms have been introduced to propose the large-scale GDM methods, which include the preference clustering approach [59], hierarchical clustering approach [60], and k-means algorithm [26]. Although these existing methods can deal with the large-scale evaluation information effectively, their operation processes are relatively complex, which will make the clustering process of large-scale decision makers more difficult to manage in the GSS problem. In contrast, the clustering approach based on the similarity measure is more appropriate to solve this situation due to its features of simplicity and effectiveness [61]. Therefore, we can develop the similarity measure 
of q-RIVOFS to construct a novel clustering approach for implementing the clustering process in the large-scale GSS problem.

Step 1. Normalize the individual q-RIVOF evaluation matrices $\boldsymbol{F}^{k}$.

During the GSS procedure, the criteria can be separated into the cost type and benefit type. Hence, before the clustering process, we should transform the evaluation information concerning different types of criteria into the unified form. Then, the individual evaluation matrices $F^{k}$ can be converted into the normalized q-RIVOF evaluation matrices $Q^{k}=\left(a_{i j}^{k}\right)_{m \times n}$ as

$$
a_{i j}^{k}=\left(\left[\mu_{i j}^{k-}, \mu_{i j}^{k+}\right],\left[v_{i j}^{k-}, v_{i j}^{k+}\right]\right)= \begin{cases}\left(\left[\bar{v}_{i j}^{k-}, \bar{v}_{i j}^{k+}\right],\left[\bar{\mu}_{i j}^{k-}, \bar{\mu}_{i j}^{k+}\right]\right) & \text { if } C_{j} \text { is the cost type; } \\ \left(\left[\bar{\mu}_{i j}^{k-}, \bar{\mu}_{i j}^{k+}\right],\left[\bar{v}_{i j}^{k-}, \bar{v}_{i j}^{k+}\right]\right) & \text { if } C_{j} \text { is the benefit type. }\end{cases}
$$

Step 2. Cluster the evaluation information into several subgroups.

Inspired by the literature [61], similarity measure is the basis of the clustering approach, thus, we define the similarity measure between different q-RIVOFNs as follows:

Definition 8. Let $a_{1}=\left(\left[\mu_{1}^{-}, \mu_{1}^{+}\right],\left[v_{1}^{-}, v_{1}^{+}\right]\right)$and $a_{2}=\left(\left[\mu_{2}^{-}, \mu_{2}^{+}\right],\left[v_{2}^{-}, v_{2}^{+}\right]\right)$be two q-RIVOFNs, then the similarity measure between them can be defined by:

$$
S M\left(a_{1}, a_{2}\right)=1-d_{M}\left(a_{1}, a_{2}\right),
$$

where $d_{M}\left(a_{1}, a_{2}\right)$ is the Minkowski distance between $q$-RIVOFNs above. Furthermore, let $Q^{1}=\left(a_{i j}^{1}\right)_{m \times n}$ and $Q^{2}=\left(a_{i j}^{2}\right)_{m \times n}$ be two $q$-RIVOF evaluation matrices, then the similarity measure between them is given by:

$$
S M\left(Q^{1}, Q^{2}\right)=\frac{1}{m n} \sum_{i=1}^{m} \sum_{j=1}^{n} \operatorname{SM}\left(a_{i j^{\prime}}^{1}, a_{i j}^{2}\right)=\frac{1}{m n} \sum_{i=1}^{m} \sum_{j=1}^{n}\left(1-d_{M}\left(a_{i j}^{1}, a_{i j}^{2}\right)\right) .
$$

Another important segment is how to determine an appropriate threshold, which can guide the large-scale decision makers to be separated into several subgroups. Based on the literature [61,62], we can utilize the majority principle to construct the clustering threshold as

$$
\bar{\lambda}=\min _{s, t=1,2, \ldots, l ; ; \neq t} S M\left(Q^{s}, Q^{t}\right)+\frac{2}{3}\left(\max _{s, t=1,2, \ldots, l ; s \neq t} S M\left(Q^{s}, Q^{t}\right)-\min _{s, t=1,2, \ldots, l ; s \neq t} S M\left(Q^{s}, Q^{t}\right)\right),
$$

where $S M\left(Q^{s}, Q^{t}\right)$ is the similarity measure between the normalized evaluation matrices $Q^{s}$ and $Q^{t}$ based on Definition 8.

Subsequently, we can utilize the predefined clustering threshold $\bar{\lambda}(\bar{\lambda} \in[0,1])$ to divide the evaluation matrices $Q^{k}$ into several subgroups $S_{K}(K=1,2, \ldots, L)$, and the number of decision makers in subgroup $S_{K}$ is assumed as $l_{K}$. To determine a more reasonable ranking, three principles should be followed during the clustering process, which include:

(1) Whether $\operatorname{SM}\left(Q^{s}, Q^{t}\right) \geq \bar{\lambda}$, then the evaluation matrices $Q^{s}$ and $Q^{t}$ are classified into the same subgroup;

(2) It must be guaranteed that at least three subgroups of evaluation information are maintained, in which the extreme case of two opposite subgroups exist can be avoided;

(3) The number of decision makers in each subgroup should exceed one; otherwise, the single decision maker is advised to withdraw from the evaluation of green suppliers [59].

\subsection{Aggregation Process of Individual Evaluation Information}

Since the large-scale evaluation information is clustered into several subgroups, the next issue is to obtain a collective q-RIVOF evaluation matrix of green suppliers, which can be implemented by 
two steps. First, the evaluation information in the same subgroup should be aggregated to obtain the subgroup q-RIVOF evaluation matrix; then, we can determine the collective q-RIVOF evaluation matrix of green suppliers combined with the subgroup evaluation matrices and the weights of subgroups.

Step 3. Obtain the subgroup evaluation matrices $R^{K}$

For the decision makers in the same subgroup $S_{K}$, the similarity level between them is relatively high. Thus, each decision maker in the subgroup $S_{K}$ can be regarded as equally important. Hence, we can assume the weight vector of decision makers in the subgroup $S_{K}$ as $w^{K}=\left(1 / l_{K}, 1 / l_{K}, \ldots, 1 / l_{K}\right)^{T}$ and utilize the q-RIVOFWA operator to aggregate their evaluation information; subsequently, the subgroup evaluation matrices $\boldsymbol{R}^{K}=\left(r_{i j}^{K}\right)_{m \times n}$ can be obtained from

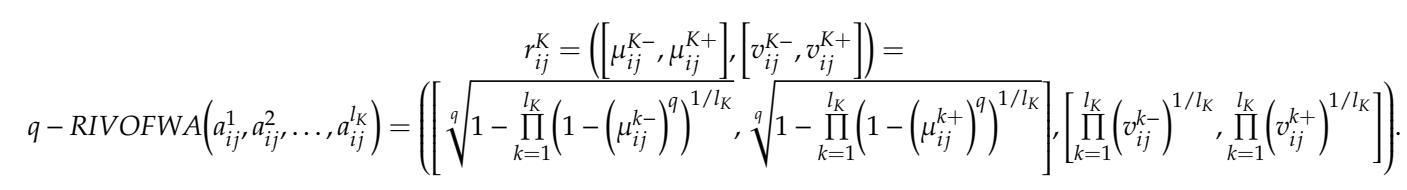

Step 4. Calculate the weights of subgroups

Before the aggregation of the subgroup evaluation matrices $R^{K}$, we should determine the weight vector of subgroups. According to the literature $[63,64]$, the consensus level between decision makers is a critical factor in measuring the rationality of ranking result in GDM process, and a ranking with a high consensus level is more desirable. Therefore, we can utilize the consensus degree to compute the weight vector of subgroups; i.e., the larger the similarity measure between a subgroup with the other subgroups, the larger the weights of the subgroup. Then, the weights of subgroups can be determined as

$$
\lambda^{K}=\frac{\sum_{T=1}^{L} S M\left(\boldsymbol{R}^{K}, \boldsymbol{R}^{T}\right)}{\sum_{K=1}^{K} \sum_{T=1}^{L} S M\left(\boldsymbol{R}^{K}, \boldsymbol{R}^{T}\right)} .
$$

Step 5. Obtain the collective evaluation matrix $R^{c}$

Once the subgroup evaluation matrices $\boldsymbol{R}^{K}$ and the weights of subgroups $\lambda^{K}$ are obtained, we can utilize the q-RIVOFWA operator to determine the collective evaluation matrix $\boldsymbol{R}^{\boldsymbol{c}}=\left(r_{i j}^{c}\right)_{m \times n}$ as

$$
\begin{gathered}
r_{i j}^{c}=\left(\left[\mu_{i j}^{c-}, \mu_{i j}^{c+}\right],\left[v_{i j}^{c-}, v_{i j}^{c+}\right]\right)= \\
q-\operatorname{RIVOFWA}\left(a_{i j^{\prime}}^{1} a_{i j}^{2}, \ldots, a_{i j}^{L}\right)=\left(\left[\sqrt[q]{1-\prod_{K=1}^{L}\left(1-\left(\mu_{i j}^{K-}\right)^{q}\right)^{\lambda^{K}}}, \sqrt[q]{1-\prod_{K=1}^{L}\left(1-\left(\mu_{i j}^{K+}\right)^{q}\right)^{\lambda^{K}}}\right],\left[\prod_{K=1}^{L}\left(v_{i j}^{K-}\right)^{\lambda^{K}}, \prod_{K=1}^{L}\left(v_{i j}^{K+}\right)^{\lambda^{K}}\right]\right) .
\end{gathered}
$$

\subsection{Determination Process of the Criteria Weights}

The weights of criteria also play a key role in ranking green suppliers. Thus, we construct the weighted entropy measure of q-RIVOFNs to obtain the weight vector of criteria. Inspired by the literature [65], we put forward the entropy measure of q-RIVOFN as in the following.

Definition 9. Let $a=\left(\left[\mu^{-}, \mu^{+}\right],\left[v^{-}, v^{+}\right]\right)$be a $q$-RIVOFN, then the entropy measure of a, i.e., $\varepsilon(a)$ can be given by

$$
\varepsilon(a)=1-d_{M}\left(a, a^{c}\right),
$$

where $d_{M}\left(a, a^{c}\right)$ is the Minkowski distance between the $q$-RIVOFN $a$ and its complementary $q$-RIVOFN.

Subsequently, the weighted entropy measure of q-RIVOFNs can be developed. 
Definition 10. Let $A=\left\{a_{1}, a_{2}, \ldots, a_{n}\right\}$ be a set of $q$-RIVOFNs and $\varepsilon\left(a_{j}\right)(j=1,2, \ldots, n)$ be the entropy measure of $a_{j}$, thus

$$
E(A)=\sum_{j=1}^{n} w_{j} \varepsilon\left(a_{j}\right)
$$

is called the weighted entropy measure of set $A=\left\{a_{1}, a_{2}, \ldots, a_{n}\right\}$, where $w_{j}$ are the weights of $q$-RIVOFNs and satisfy the conditions of $0 \leq w_{j} \leq 1$ and $\sum_{j=1}^{n} w_{j}=1$.

According to the definitions above, the weights of criteria can be computed objectively during the GSS process.

Step 6. Compute the overall weighted entropy, concerning different criteria

Combined with the weights of subgroups and the subgroup evaluation matrices, the overall weighted entropy concerning different criteria can be computed by

$$
E\left(C_{j}\right)=\sum_{K=1}^{L} \lambda^{K} \sum_{i=1}^{m} \varepsilon\left(r_{i j}^{K}\right) .
$$

Step 7. Obtain the weights of criteria

According to the entropy theory, once the weighted entropy value with respect to a criteria is smaller across the potential green suppliers, a larger weight should be assigned to the criteria [30]; i.e., the smaller the value of $E\left(C_{j}\right)$, the larger weight the criteria $C_{j}$. Hence, the weights of criteria can be determined by

$$
w_{j}=\frac{\sum_{K=1}^{L} \lambda^{K} \sum_{i=1}^{m}\left(1-\varepsilon\left(r_{i j}^{K}\right)\right)}{\sum_{j=1}^{n} \sum_{K=1}^{L} \lambda^{K} \sum_{i=1}^{m}\left(1-\varepsilon\left(r_{i j}^{K}\right)\right)} .
$$

\subsection{Ranking Process Using the q-RIVOF-MULTIMOORA Approach}

The traditional MULTIMOORA approach is composed of the ratio system, the reference point approach, and the full multiplicative form, and is a powerful tool to obtain a ranking with strong robustness. To determine the best green supplier, we construct the improved MULTIMOORA approach under the q-RIVOF environment, in which the q-RIVOFWA and q-RIVOFWG operators are introduced to implement the ratio system and reference point approach, respectively, and the weighted Chebyshev distance of q-RIVOFNs is utilized in the improved reference point approach. Hence, the MULTIMOORA approach can be improved to adapt to the q-RIVOF environment, and the weights of criteria are also highlighted during the ranking process. Consequently, the q-RIVOF-MULTIMOORA approach can be implemented by the following steps:

Step 8. The q-RIVOF ratio system

Combined with the collective evaluation matrix $\boldsymbol{R}^{c}$ and the weights of criteria $w_{j}$, the comprehensive utilities of green supplier $G_{i}$ with respect to all the criteria can be computed by

$$
\begin{gathered}
\widetilde{y}^{*}\left(G_{i}\right)=q-\operatorname{RIVOFWA}\left(r_{i 1^{c}}^{c}, r_{i 2^{\prime}}^{c}, \ldots, r_{i n}^{c}\right) \\
=\left(\left[\sqrt[q]{1-\prod_{j=1}^{n}\left(1-\left(\mu_{i j}^{c-}\right)^{q}\right)^{w_{i}}}, \sqrt[q]{1-\prod_{j=1}^{n}\left(1-\left(\mu_{i j}^{c+}\right)^{q}\right)^{w_{i}}}\right],\left[\prod_{j=1}^{n}\left(v_{i j}^{c-}\right)^{w_{i}}, \prod_{j=1}^{n}\left(v_{i j}^{c+}\right)^{w_{i}}\right]\right) .
\end{gathered}
$$

Obviously, the comprehensive utilities of green suppliers $\widetilde{y}^{*}\left(G_{i}\right)$ are the q-RIVOFNs; thus, we can compare the values of them to rank green suppliers. The larger the score value of $\widetilde{y}^{*}\left(G_{i}\right)$, the higher the ranking of green supplier $G_{i}$.

Step 9. The q-RIVOF reference point approach 
The Minkowski measure [66] can be introduced to calculate the distance between the collective evaluation information of green suppliers concerning each criterion and the positive reference point $r^{*}=([1,1],[0,0])$ as follows:

$$
d\left(r^{*}, G_{i}\right)=\left\{\sum_{j=1}^{n}\left[d\left(r^{*}, r_{i j}^{c}\right)\right]^{\gamma}\right\}^{1 / \gamma}, \gamma \in N^{+} .
$$

According to the literature [27], the robustness of the decision making problems, by Minkowski measurement, increases by enhancing the value of $\gamma$, thus we set $\gamma \rightarrow \infty$, the distance above is reduced to the Chebyshev distance as

$$
d\left(r^{*}, G_{i}\right)=\max _{1 \leq j \leq n} d\left(r^{*}, r_{i j}^{c}\right) .
$$

Subsequently, considering the weights of criteria $w_{j}$, the weighted Chebyshev distance between the collective evaluation information of green suppliers concerning each criterion, and the positive reference point can be obtained as in the following:

$$
d\left(r^{*}, G_{i}\right)=\max _{1 \leq j \leq n} w_{j} d\left(r^{*}, r_{i j}^{c}\right)=\max _{1 \leq j \leq n} \frac{w_{j}}{4}\left(\left|1-\mu_{i j}^{c-}\right|+\left|1-\mu_{i j}^{c+}\right|+\left|v_{i j}^{c-}\right|+\left|v_{i j}^{c+}\right|\right) .
$$

Accordingly, the smaller the weighted Chebyshev distance $d\left(r^{*}, G_{i}\right)$, the higher the ranking of green supplier $G_{i}$.

Step 10. The q-RIVOF full multiplicative form

Similar to the q-RIVOF ratio system, the multiplicative utilities of green supplier $G_{i}$ with respect to all the criteria can be computed by

$$
\begin{gathered}
\widetilde{U}^{*}\left(G_{i}\right)=q-\operatorname{RIVOFWG}\left(r_{i 1}^{c}, r_{i 2}^{c}, \ldots, r_{i n}^{c}\right) \\
=\left(\left[\prod_{j=1}^{n}\left(\mu_{i j}^{c-}\right)^{w_{i}}, \prod_{j=1}^{n}\left(\mu_{i j}^{c+}\right)^{w_{i}}\right],\left[\sqrt[q]{1-\prod_{j=1}^{n}\left(1-\left(v_{i j}^{c}\right)^{q}\right)^{w_{i}}}, \sqrt[q]{1-\prod_{j=1}^{n}\left(1-\left(v_{i j}^{c+}\right)^{q}\right)^{w_{i}}}\right]\right) .
\end{gathered}
$$

Hence, we can compare the values of multiplicative utilities $\widetilde{U}^{*}\left(G_{i}\right)$ to determine the ranking of green suppliers; the larger the score value of $\widetilde{U}^{*}\left(G_{i}\right)$, the higher the ranking of green supplier $G_{i}$.

Step 11. Determine the final ranking according to the dominance theory

Since the three rankings of green suppliers are obtained by the q-RIVOF ratio system, the q-RIVOF reference point approach, and the q-RIVOF full multiplicative form, the final ranking result can be determined combined with the dominance theory [31].

\section{Case Study}

To investigate the feasibility and superiority of the proposed large-scale GSS method, we introduce the numerical example explored in the literature [23] in this section. To reduce the $\mathrm{CO}_{2}$ emissions during the production process for improving the environmental performance, a manufacturing enterprise plans to choose an appropriate supplier for cooperating. Considering the importance and complexity of this GSS issue, a large-scale group of decision makers $D M_{k}(k=1,2, \ldots, 20)$ is constructed by the enterprise, and they evaluate five potential green suppliers $G_{i}(i=1,2,3,4,5)$ concerning four criteria $C_{j}(j=1,2,3,4)$. Namely, the product quality factor $\left(C_{1}\right)$, i.e., the quality level of raw materials for production; the environmental factor $\left(C_{2}\right)$, i.e., the environmental performance of raw materials for production; the delivery factor $\left(C_{3}\right)$, i.e., the flexibility level in the delivery of raw materials for production; and the price factor $\left(C_{4}\right)$, i.e., the price of raw materials for production, where $C_{4}$ is the cost type criteria, and the others are the benefit type criteria. The structure of determining the best green supplier in this numerical example is presented in Figure 3. According to the literature [19,29], we can construct the relationships between linguistic terms and their corresponding q-RIVOFNs $(q=3)$ as 
shown in Table 1. Twenty decision makers use the linguistic terms to evaluate green suppliers as presented in Table 2; then, the linguistic terms can be transformed into the evaluation matrices of green suppliers $\boldsymbol{F}^{k}=\left(\bar{a}_{i j}^{k}\right)_{5 \times 4}$. It is remarkable that we utilize the Hamming distance $(p=1)$ between q-RIVOFNs reduced by Minkowski distance to implement the GSS process. Subsequently, the ranking of green suppliers can be determined by the proposed approach as in the following subsection.

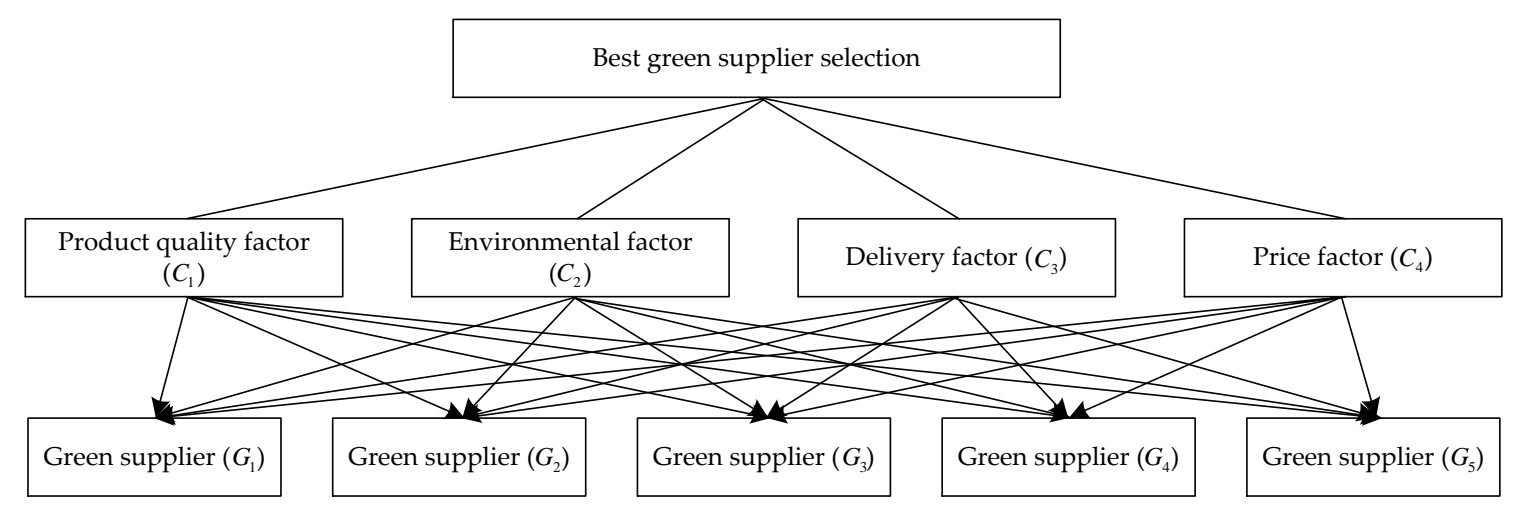

Figure 3. Structure of determining the best green supplier.

Table 1. Linguistic terms and the corresponding q-rung interval-valued orthopair fuzzy numbers (q-RIVOFNs).

\begin{tabular}{cc}
\hline Linguistic Terms & Corresponding q-RIVOFNs \\
\hline Extremely High (EH) & $([0.90,0.95],[0.10,0.15])$ \\
Very High (VH) & $([0.80,0.85],[0.20,0.25])$ \\
High $(\mathrm{H})$ & $([0.70,0.75],[0.30,0.35])$ \\
Medium High $(\mathrm{MH})$ & $([0.60,0.65],[0.40,0.45])$ \\
Medium $(\mathrm{M})$ & $([0.50,0.55],[0.50,0.55])$ \\
Medium Low (ML) & $([0.40,0.45],[0.60,0.65])$ \\
Low $(\mathrm{L})$ & $([0.30,0.35],[0.70,0.75])$ \\
Very Low $(\mathrm{VL})$ & $([0.20,0.25],[0.80,0.85])$ \\
Extremely Low (EL) & $([0.10,0.15],[0.90,0.95])$ \\
\hline
\end{tabular}

Table 2. Linguistic terms of decision makers.

\begin{tabular}{cccccc}
\hline \multirow{2}{*}{ Decision Makers } & \multirow{2}{*}{ Green Suppliers } & \multicolumn{4}{c}{ Criteria } \\
\cline { 2 - 6 } & & $C_{1}$ & $C_{2}$ & $C_{3}$ & $C_{4}$ \\
\hline \multirow{5}{*}{$D M_{1}$} & $G_{1}$ & $\mathrm{H}$ & $\mathrm{M}$ & $\mathrm{H}$ & $\mathrm{L}$ \\
& $G_{2}$ & $\mathrm{M}$ & $\mathrm{MH}$ & $\mathrm{VH}$ & $\mathrm{EL}$ \\
& $G_{3}$ & $\mathrm{ML}$ & $\mathrm{VH}$ & $\mathrm{M}$ & $\mathrm{M}$ \\
& $G_{4}$ & $\mathrm{VH}$ & $\mathrm{M}$ & $\mathrm{M}$ & $\mathrm{MH}$ \\
& $G_{5}$ & $\mathrm{~L}$ & $\mathrm{ML}$ & $\mathrm{ML}$ & $\mathrm{H}$ \\
\hline \multirow{5}{*}{$D M_{2}$} & $G_{1}$ & $\mathrm{VL}$ & $\mathrm{H}$ & $\mathrm{ML}$ & $\mathrm{L}$ \\
& $G_{2}$ & $\mathrm{MH}$ & $\mathrm{L}$ & $\mathrm{VH}$ & $\mathrm{MH}$ \\
& $G_{3}$ & $\mathrm{M}$ & $\mathrm{VH}$ & $\mathrm{MH}$ & $\mathrm{VH}$ \\
& $G_{4}$ & $\mathrm{VH}$ & $\mathrm{VH}$ & $\mathrm{MH}$ & $\mathrm{MH}$ \\
& $G_{5}$ & $\mathrm{H}$ & $\mathrm{ML}$ & $\mathrm{ML}$ & $\mathrm{H}$ \\
\hline \multirow{5}{*}{$D M_{3}$} & $G_{1}$ & $\mathrm{VH}$ & $\mathrm{M}$ & $\mathrm{MH}$ & $\mathrm{EL}$ \\
& $G_{2}$ & $\mathrm{M}$ & $\mathrm{MH}$ & $\mathrm{VH}$ & $\mathrm{EL}$ \\
& $G_{3}$ & $\mathrm{ML}$ & $\mathrm{VH}$ & $\mathrm{M}$ & $\mathrm{MH}$ \\
& $G_{4}$ & $\mathrm{VH}$ & $\mathrm{M}$ & $\mathrm{ML}$ & $\mathrm{MH}$ \\
& $G_{5}$ & $\mathrm{VL}$ & $\mathrm{ML}$ & $\mathrm{ML}$ & $\mathrm{MH}$ \\
\hline
\end{tabular}


Table 2. Cont.

\begin{tabular}{|c|c|c|c|c|c|}
\hline \multirow{2}{*}{ Decision Makers } & \multirow{2}{*}{ Green Suppliers } & \multicolumn{4}{|c|}{ Criteria } \\
\hline & & $C_{1}$ & $C_{2}$ & $C_{3}$ & $C_{4}$ \\
\hline \multirow{5}{*}{$D M_{4}$} & $G_{1}$ & $\mathrm{H}$ & M & $\mathrm{EH}$ & $\mathrm{EH}$ \\
\hline & $G_{2}$ & ML & $\mathrm{H}$ & VL & EL \\
\hline & $G_{3}$ & ML & VL & $\mathrm{M}$ & ML \\
\hline & $G_{4}$ & $\mathrm{~L}$ & ML & $\mathrm{M}$ & VL \\
\hline & $G_{5}$ & $\mathrm{~L}$ & $\mathrm{H}$ & MH & $\mathrm{L}$ \\
\hline \multirow{5}{*}{$D M_{5}$} & $G_{1}$ & $\mathrm{H}$ & M & $\mathrm{H}$ & $\mathrm{L}$ \\
\hline & $G_{2}$ & $\mathrm{M}$ & $\mathrm{M}$ & $\mathrm{EH}$ & EL \\
\hline & $G_{3}$ & ML & $\mathrm{VH}$ & ML & $\mathrm{M}$ \\
\hline & $G_{4}$ & $\mathrm{VH}$ & ML & $\mathrm{M}$ & $\mathrm{H}$ \\
\hline & $G_{5}$ & $\mathrm{~L}$ & ML & ML & $\mathrm{MH}$ \\
\hline \multirow{5}{*}{$D M_{6}$} & $G_{1}$ & $\mathrm{H}$ & ML & $\mathrm{EH}$ & $\mathrm{EH}$ \\
\hline & $G_{2}$ & ML & $\mathrm{MH}$ & VL & EL \\
\hline & $G_{3}$ & ML & VL & $\mathrm{MH}$ & ML \\
\hline & $G_{4}$ & $\mathrm{~L}$ & ML & $\mathrm{M}$ & $\mathrm{L}$ \\
\hline & $G_{5}$ & $\mathrm{~L}$ & $\mathrm{H}$ & $\mathrm{H}$ & $\mathrm{L}$ \\
\hline \multirow{5}{*}{$D M_{7}$} & $G_{1}$ & $\mathrm{~L}$ & $\mathrm{H}$ & ML & $\mathrm{L}$ \\
\hline & $G_{2}$ & M & $\mathrm{L}$ & $\mathrm{VH}$ & $\mathrm{H}$ \\
\hline & $G_{3}$ & $\mathrm{M}$ & $\mathrm{H}$ & $\mathrm{MH}$ & $\mathrm{VH}$ \\
\hline & $G_{4}$ & $\mathrm{VH}$ & $\mathrm{VH}$ & $\mathrm{M}$ & $\mathrm{MH}$ \\
\hline & $G_{5}$ & $\mathrm{H}$ & ML & ML & $\mathrm{H}$ \\
\hline \multirow{5}{*}{$D M_{8}$} & $G_{1}$ & $\mathrm{VH}$ & $M$ & $\mathrm{EH}$ & $\mathrm{EH}$ \\
\hline & $G_{2}$ & ML & $\mathrm{H}$ & VL & EL \\
\hline & $G_{3}$ & ML & $\mathrm{L}$ & $\mathrm{MH}$ & ML \\
\hline & $G_{4}$ & ML & $\mathrm{L}$ & $\mathrm{M}$ & VL \\
\hline & $G_{5}$ & $\mathrm{~L}$ & $\mathrm{H}$ & $\mathrm{MH}$ & $\mathrm{L}$ \\
\hline \multirow{5}{*}{$D M_{9}$} & $G_{1}$ & $\mathrm{H}$ & $\mathrm{MH}$ & $\mathrm{MH}$ & $\mathrm{L}$ \\
\hline & $G_{2}$ & $\mathrm{M}$ & $\mathrm{MH}$ & $\mathrm{VH}$ & EL \\
\hline & $G_{3}$ & ML & $\mathrm{VH}$ & $\mathrm{M}$ & $\mathrm{MH}$ \\
\hline & $G_{4}$ & $\mathrm{VH}$ & ML & M & $\mathrm{MH}$ \\
\hline & $G_{5}$ & $\mathrm{~L}$ & ML & $\mathrm{L}$ & $\mathrm{EH}$ \\
\hline \multirow{5}{*}{$D M_{10}$} & $G_{1}$ & $\mathrm{H}$ & $\mathrm{M}$ & $\mathrm{H}$ & $\mathrm{L}$ \\
\hline & $G_{2}$ & $\mathrm{M}$ & $\mathrm{MH}$ & $\mathrm{VH}$ & EL \\
\hline & $G_{3}$ & $\mathrm{~L}$ & $\mathrm{VH}$ & ML & $\mathrm{M}$ \\
\hline & $G_{4}$ & $\mathrm{H}$ & $\mathrm{M}$ & $\mathrm{M}$ & $\mathrm{MH}$ \\
\hline & $G_{5}$ & $\mathrm{~L}$ & ML & $\mathrm{M}$ & $\mathrm{H}$ \\
\hline \multirow{5}{*}{$D M_{11}$} & $G_{1}$ & $\mathrm{H}$ & $\mathrm{H}$ & $\mathrm{H}$ & $\mathrm{L}$ \\
\hline & $G_{2}$ & $\mathrm{MH}$ & $\mathrm{L}$ & $\mathrm{L}$ & EL \\
\hline & $G_{3}$ & $\mathrm{VH}$ & $\mathrm{VH}$ & $\mathrm{M}$ & EL \\
\hline & $G_{4}$ & $\mathrm{VH}$ & VL & $\mathrm{M}$ & $\mathrm{H}$ \\
\hline & $G_{5}$ & $\mathrm{VH}$ & $\mathrm{H}$ & $\mathrm{L}$ & $\mathrm{L}$ \\
\hline \multirow{5}{*}{$D M_{12}$} & $G_{1}$ & VL & $\mathrm{H}$ & ML & $\mathrm{L}$ \\
\hline & $G_{2}$ & $\mathrm{MH}$ & $\mathrm{L}$ & $\mathrm{VH}$ & $\mathrm{MH}$ \\
\hline & $G_{3}$ & ML & $\mathrm{H}$ & $\mathrm{H}$ & $\mathrm{VH}$ \\
\hline & $G_{4}$ & $\mathrm{VH}$ & $\mathrm{VH}$ & MH & $\mathrm{MH}$ \\
\hline & $G_{5}$ & $\mathrm{MH}$ & ML & ML & $\mathrm{MH}$ \\
\hline \multirow{5}{*}{$D M_{13}$} & $G_{1}$ & $\mathrm{H}$ & $M$ & $\mathrm{EH}$ & $\mathrm{EH}$ \\
\hline & $G_{2}$ & $\mathrm{~L}$ & $\mathrm{H}$ & VL & EL \\
\hline & $G_{3}$ & ML & VL & $\mathrm{M}$ & ML \\
\hline & $G_{4}$ & ML & ML & $\mathrm{MH}$ & VL \\
\hline & $G_{5}$ & $\mathrm{~L}$ & $\mathrm{MH}$ & $\mathrm{MH}$ & ML \\
\hline
\end{tabular}


Table 2. Cont.

\begin{tabular}{|c|c|c|c|c|c|}
\hline \multirow{2}{*}{ Decision Makers } & \multirow{2}{*}{ Green Suppliers } & \multicolumn{4}{|c|}{ Criteria } \\
\hline & & $C_{1}$ & $C_{2}$ & $C_{3}$ & $C_{4}$ \\
\hline \multirow{5}{*}{$D M_{14}$} & $G_{1}$ & $\mathrm{H}$ & ML & $\mathrm{H}$ & $\mathrm{VH}$ \\
\hline & $G_{2}$ & $\mathrm{VH}$ & $\mathrm{MH}$ & VL & EL \\
\hline & $G_{3}$ & ML & $\mathrm{EH}$ & $\mathrm{MH}$ & $\mathrm{MH}$ \\
\hline & $G_{4}$ & $\mathrm{M}$ & $\mathrm{EH}$ & VL & ML \\
\hline & $G_{5}$ & ML & ML & ML & $\mathrm{H}$ \\
\hline \multirow{5}{*}{$D M_{15}$} & $G_{1}$ & VL & $\mathrm{H}$ & ML & ML \\
\hline & $G_{2}$ & $\mathrm{MH}$ & ML & $\mathrm{VH}$ & $\mathrm{MH}$ \\
\hline & $G_{3}$ & $\mathrm{M}$ & VH & MH & $\mathrm{VH}$ \\
\hline & $G_{4}$ & $\mathrm{H}$ & $\mathrm{VH}$ & $\mathrm{MH}$ & $\mathrm{H}$ \\
\hline & $G_{5}$ & $\mathrm{H}$ & ML & $\mathrm{L}$ & $\mathrm{H}$ \\
\hline \multirow{5}{*}{$D M_{16}$} & $G_{1}$ & $\mathrm{H}$ & $M$ & $\mathrm{H}$ & $\mathrm{EH}$ \\
\hline & $G_{2}$ & ML & $\mathrm{H}$ & VL & $\mathrm{L}$ \\
\hline & $G_{3}$ & ML & VL & $\mathrm{VH}$ & $\mathrm{L}$ \\
\hline & $G_{4}$ & $\mathrm{~L}$ & $\mathrm{M}$ & $\mathrm{M}$ & VL \\
\hline & $G_{5}$ & $\mathrm{~L}$ & $\mathrm{H}$ & $\mathrm{MH}$ & $\mathrm{L}$ \\
\hline \multirow{5}{*}{$D M_{17}$} & $G_{1}$ & $\mathrm{VH}$ & $\mathrm{M}$ & $\mathrm{H}$ & $\mathrm{L}$ \\
\hline & $G_{2}$ & $\mathrm{M}$ & $\mathrm{MH}$ & MH & EL \\
\hline & $G_{3}$ & ML & $\mathrm{VH}$ & $\mathrm{M}$ & $\mathrm{MH}$ \\
\hline & $G_{4}$ & $\mathrm{VH}$ & $\mathrm{M}$ & $\mathrm{M}$ & $\mathrm{H}$ \\
\hline & $G_{5}$ & VL & ML & $\mathrm{M}$ & $\mathrm{H}$ \\
\hline \multirow{5}{*}{$D M_{18}$} & $G_{1}$ & $\mathrm{H}$ & ML & $\mathrm{VH}$ & $\mathrm{VH}$ \\
\hline & $G_{2}$ & $\mathrm{H}$ & $\mathrm{L}$ & $\mathrm{L}$ & $\mathrm{VH}$ \\
\hline & $G_{3}$ & $\mathrm{MH}$ & $\mathrm{VH}$ & M & $\mathrm{MH}$ \\
\hline & $G_{4}$ & $\mathrm{VH}$ & $\mathrm{EH}$ & $\mathrm{M}$ & $\mathrm{VH}$ \\
\hline & $G_{5}$ & VL & $\mathrm{ML}$ & $\mathrm{VH}$ & $\mathrm{H}$ \\
\hline \multirow{5}{*}{$D M_{19}$} & $G_{1}$ & $\mathrm{~L}$ & $\mathrm{MH}$ & ML & $\mathrm{L}$ \\
\hline & $G_{2}$ & $\mathrm{MH}$ & VL & $\mathrm{VH}$ & $\mathrm{MH}$ \\
\hline & $G_{3}$ & $\mathrm{M}$ & $\mathrm{H}$ & $\mathrm{MH}$ & $\mathrm{VH}$ \\
\hline & $G_{4}$ & $\mathrm{VH}$ & $\mathrm{VH}$ & MH & $\mathrm{MH}$ \\
\hline & $G_{5}$ & $\mathrm{H}$ & ML & $\mathrm{L}$ & $\mathrm{H}$ \\
\hline \multirow{5}{*}{$D M_{20}$} & $G_{1}$ & $\mathrm{EH}$ & $\mathrm{M}$ & EL & $\mathrm{L}$ \\
\hline & $G_{2}$ & ML & $\mathrm{VH}$ & MH & EL \\
\hline & $G_{3}$ & $\mathrm{VH}$ & $\mathrm{VH}$ & ML & $\mathrm{M}$ \\
\hline & $G_{4}$ & $\mathrm{VH}$ & ML & $\mathrm{VH}$ & MH \\
\hline & $G_{5}$ & $\mathrm{H}$ & $\mathrm{VH}$ & $\mathrm{H}$ & $\mathrm{L}$ \\
\hline
\end{tabular}

\subsection{Implementation}

Step 1. Normalize the individual q-RIVOF evaluation matrices $\boldsymbol{F}^{k}$.

Because of the criteria $C_{4}$ is the cost type criteria, we can utilize the Equation (17) to obtain the normalized q-RIVOF evaluation matrices $Q^{k}=\left(a_{i j}^{k}\right)_{5 \times 4}$.

Step 2. Cluster the evaluation information into several subgroups.

According to the normalized evaluation matrices $Q^{k}$, the similarity measures between them can be computed by Equation (19). Then, the clustering threshold $\bar{\lambda}$, which is used to divide the large-scale group of decision makers into several subgroups, can be obtained based on Equation (20) as $\bar{\lambda}=0.8633$. Combined with the principles during the clustering process, the large-scale decision makers can be divided into three subgroups as follows:

$$
S_{1}=\left\{D M_{1}, D M_{3}, D M_{5}, D M_{9}, D M_{10}, D M_{17}\right\} ;
$$




$$
\begin{gathered}
S_{2}=\left\{D M_{2}, D M_{7}, D M_{12}, D M_{15}, D M_{19}\right\} ; \\
S_{3}=\left\{D M_{4}, D M_{6}, D M_{8}, D M_{13}, D M_{16}\right\} .
\end{gathered}
$$

It is worth noting that the evaluation information of decision makers $D M_{11}, D M_{14}, D M_{18}$, and $D M_{20}$ is ignored during the subsequent decision making process due to the low similarity degrees between their evaluation information and that of other decision makers.

Step 3. Obtain the subgroup evaluation matrices $R^{K}$

Assume that decision makers in the subgroup $S_{K}$ are regarded as equally important, then the subgroup evaluation matrices $\boldsymbol{R}^{K}=\left(r_{i j}^{K}\right)_{5 \times 4}(K=1,2,3)$ can be obtained using the q-RIVOFWA operator, as presented in Tables 3-5.

Table 3. Subgroup evaluation matrix $\boldsymbol{R}^{1}$.

\begin{tabular}{ccccc}
\hline Green Suppliers & $C_{1}$ & $C_{2}$ & $C_{3}$ & $C_{4}$ \\
\hline \multirow{2}{*}{$G_{1}$} & $([0.7399,0.7909]$, & $([0.5203,0.5703]$, & $([0.6718,0.7221]$, & $([0.7566,0.8154]$, \\
& $[0.2621,0.3129])$ & $[0.4817,0.5319])$ & $[0.3302,0.3806])$ & $[0.2498,0.3039])$ \\
\hline \multirow{2}{*}{$G_{2}$} & $([0.5000,0.5500]$, & $([0.5863,0.6363]$, & $([0.8048,0.8604]$, & $([0.9000,0.9500]$, \\
& $[0.5000,0.5500])$ & $[0.4152,0.4653])$ & $[0.2000,0.2532])$ & $[0.1000,0.1500])$ \\
\hline \multirow{2}{*}{$G_{3}$} & $([0.3869,0.4367]$, & $([0.8000,0.8500]$, & $([0.4720,0.5217]$, & $([0.4563,0.5060]$, \\
& $[0.6156,0.6657])$ & $[0.2000,0.2500])$ & $[0.5313,0.5815])$ & $[0.5477,0.5979])$ \\
\hline \multirow{2}{*}{$G_{4}$} & $([0.7869,0.8374]$, & $([0.4720,0.5217]$, & $([0.4865,0.5363]$, & $([0.3728,0.4223]$, \\
& $[0.2140,0.2644])$ & $[0.5313,0.5815])$ & $[0.5154,0.5655])$ & $[0.6316,0.6818])$ \\
\hline \multirow{2}{*}{$G_{5}$} & $([0.2746,0.3236]$, & $([0.4000,0.4500]$, & $([0.4288,0.4781]$, & $([0.3279,0.3753]$, \\
& $[0.7319,0.7820])$ & $[0.6000,0.6500])$ & $[0.5793,0.6296])$ & $[0.6934,0.7438])$ \\
\hline
\end{tabular}

Table 4. Subgroup evaluation matrix $R^{2}$.

\begin{tabular}{ccccc}
\hline Green Suppliers & $C_{1}$ & $C_{2}$ & $C_{3}$ & $C_{4}$ \\
\hline \multirow{2}{*}{$G_{1}$} & $([0.2501,0.2986]$, & $([0.6835,0.7337]$, & $([0.4000,0.4500]$, & $([0.6835,0.7337]$, \\
& $[0.7584,0.8085])$ & $[0.3178,0.3680])$ & $[0.6000,0.6500])$ & $[0.3178,0.3680])$ \\
\hline \multirow{2}{*}{$G_{2}$} & $([0.5834,0.6334]$, & $([0.3134,0.3619]$, & $([0.8000,0.8500]$, & $([0.3842,0.4339]$, \\
& $[0.4183,0.4684])$ & $[0.6971,0.7473])$ & $[0.2000,0.2500])$ & $[0.6188,0.6689])$ \\
\hline \multirow{2}{*}{$G_{3}$} & $([0.4836,0.5335]$, & $([0.7469,0.7980]$, & $([0.6242,0.6745]$, & $([0.2000,0.2500]$, \\
& $[0.5186,0.5687])$ & $[0.2551,0.3059])$ & $[0.3776,0.4279])$ & $[0.8000,0.8500])$ \\
\hline \multirow{2}{*}{$G_{4}$} & $([0.7841,0.7337]$, & $([0.8000,0.8500]$, & $([0.5834,0.6334]$, & $([0.3842,0.4339]$, \\
& $[0.2169,0.2674])$ & $[0.2000,0.2500])$ & $[0.4183,0.4684])$ & $[0.6188,0.6689])$ \\
\hline \multirow{2}{*}{$G_{5}$} & $([0.6835,0.7337]$, & $([0.4000,0.4500]$, & $([0.3669,0.4163]$, & $([0.3256,0.3750]$, \\
& $[0.3178,0.3680])$ & $[0.6000,0.6500])$ & $[0.6382,0.6883])$ & $[0.6787,0.7288])$ \\
\hline
\end{tabular}

Table 5. Subgroup evaluation matrix $R^{3}$.

\begin{tabular}{ccccc}
\hline Green Suppliers & $C_{1}$ & $C_{2}$ & $C_{3}$ & $C_{4}$ \\
\hline \multirow{2}{*}{$G_{1}$} & $([0.7249,0.7757]$, & $([0.4836,0.5335]$, & $([0.8779,0.9327]$, & $([0.1000,0.1500]$, \\
& $[0.2767,0.3272])$ & $[0.5186,0.5687])$ & $[0.1246,0.1777])$ & $[0.9000,0.9500])$ \\
\hline \multirow{2}{*}{$G_{2}$} & $([0.3842,0.4339]$, & $([0.6835,0.7337]$, & $([0.2000,0.2500]$, & $([0.8779,0.9327]$, \\
& $[0.6188,0.6689])$ & $[0.3178,0.3680])$ & $[0.8000,0.8500])$ & $[0.1246,0.1777])$ \\
\hline \multirow{2}{*}{$G_{3}$} & $([0.4000,0.4500]$, & $([0.2279,0.2765]$, & $([0.6341,0.6869]$, & $([0.6242,0.6745]$, \\
& $[0.6000,0.6500])$ & $[0.7789,0.8290])$ & $[0.3807,0.4335])$ & $[0.3776,0.4279])$ \\
\hline \multirow{2}{*}{$G_{4}$} & $([0.3475,0.3968]$, & $([0.4108,0.4601]$, & $([0.5242,0.5741]$, & $([0.7841,0.8347]$, \\
& $[0.6581,0.7083])$ & $[0.5966,0.6470])$ & $[0.4782,0.5284])$ & $[0.2169,0.2674])$ \\
\hline \multirow{2}{*}{$G_{5}$} & $([0.3000,0.3500]$, & $([0.6835,0.7337]$, & $([0.6242,0.6745]$, & $([0.6835,0.7337]$, \\
& $[0.7000,0.7500])$ & $[0.3178,0.3680])$ & $[0.3776,0.4279])$ & $[0.3178,0.3680])$ \\
\hline
\end{tabular}


Step 4. Determine the weights of subgroups

Since the subgroup evaluation matrices $R^{K}$ are obtained, we can compute the similarity degrees between them; then, the weights of subgroups can be calculated by Equation (22) as $\lambda=(0.347,0.330,0.323)^{T}$.

Step 5. Obtain the collective evaluation matrix $\boldsymbol{R}^{c}$

Combined with the subgroup evaluation matrices $R^{K}$ and weight vector of subgroups $\lambda$, the q-RIVOFWA operator is utilized to determine the collective evaluation matrix $R^{c}=\left(r_{i j}^{c}\right)_{5 \times 4}$, as shown in Table 6.

Table 6. Collective evaluation matrix.

\begin{tabular}{ccccc}
\hline Green Suppliers & $C_{1}$ & $C_{2}$ & $C_{3}$ & $C_{4}$ \\
\hline \multirow{2}{*}{$G_{1}$} & $([0.6607,0.7125]$, & $([0.5811,0.6316]$, & $([0.7371,0.8042]$, & $([0.6518,0.7079]$, \\
& $[0.3787,0.4342])$ & $[0.4300,0.4813])$ & $[0.2935,0.3551])$ & $[0.4092,0.4678])$ \\
\hline \multirow{2}{*}{$G_{2}$} & $([0.5054,0.5550]$, & $([0.5765,0.6262]$, & $([0.7308,0.7877]$, & $([0.8276,0.8927]$, \\
& $[0.5050,0.5557])$ & $[0.4518,0.5044])$ & $[0.3130,0.3729])$ & $[0.1959,0.2595])$ \\
\hline \multirow{2}{*}{$G_{3}$} & $([0.4281,0.4776]$, & $([0.7047,0.7579]$, & $([0.5867,0.6379]$, & $([0.4926,0.5404]$, \\
& $[0.5769,0.6271])$ & $[0.3362,0.3936])$ & $[0.4263,0.4780])$ & $[0.5504,0.6028])$ \\
\hline \multirow{2}{*}{$G_{4}$} & $([0.7182,0.7717]$, & $([0.6367,0.6910]$, & $([0.5345,0.5844]$, & $([0.6050,0.6588]$, \\
& $[0.3090,0.3649])$ & $[0.3996,0.4555])$ & $[0.4696,0.5199])$ & $[0.4442,0.5007])$ \\
\hline \multirow{2}{*}{$G_{5}$} & $([0.5108,0.5590]$, & $([0.5378,0.5878]$, & $([0.5020,0.5511]$, & $([0.5166,0.5651]$, \\
& $[0.5478,0.6016])$ & $[0.4886,0.5409])$ & $[0.5209,0.5724])$ & $[0.5351,0.5886])$ \\
\hline
\end{tabular}

Step 6. Compute the overall weighted entropy concerning different criteria

We can utilize Equation (26) to compute the overall weighted entropy concerning different criteria as

$$
E\left(C_{1}\right)=3.3402, \quad E\left(C_{2}\right)=3.4691, \quad E\left(C_{3}\right)=3.4849, \quad E\left(C_{4}\right)=2.8234
$$

Step 7. Determine the weights of criteria

Combined with Equation (27), the weight vector of criteria is computed as $w=$ $(0.241,0.223,0.220,0.316)^{T}$.

Step 8-11. Determine the final ranking of green suppliers

According to Equations (28), (31), and (32), the comprehensive utilities of green supplier $G_{i}$ with respect to all the criteria $\widetilde{y}^{*}\left(G_{i}\right)$, the weighted Chebyshev distances between the collective evaluation information of green suppliers concerning each criteria and the positive reference point $d\left(r^{*}, G_{i}\right)$, and the multiplicative utilities of green supplier $G_{i}$ concerning all the criteria $\widetilde{U}^{*}\left(G_{i}\right)$ can be calculated as presented in Table 7. Once three rankings are obtained in the relevant steps of the q-RIVOF-MULTIMOORA method; the final ranking result can be determined using the dominance theory as presented in Table 8.

Table 7. Ranking indexes of the q-rung interval-valued orthopair fuzzy multi-objective optimization on the basis of ratio analysis plus the full multiplicative form (q-RIVOF-MULTIMOORA) method.

\begin{tabular}{|c|c|c|c|c|c|}
\hline $\begin{array}{c}\text { Green } \\
\text { Suppliers }\end{array}$ & $\tilde{y}^{*}\left(G_{i}\right)$ & Score Values of $\widetilde{y}^{*}\left(G_{i}\right)$ & $d\left(r^{*}, G_{i}\right)$ & $\tilde{U}^{*}\left(G_{i}\right)$ & Score Values of $\widetilde{U}^{*}\left(G_{i}\right)$ \\
\hline$G_{1}$ & $\begin{array}{l}([0.6637,0.7223], \\
[0.3775,0.4352])\end{array}$ & 0.6332 & 0.1199 & $\begin{array}{l}([0.6549,0.7108], \\
[0.3876,0.4433])\end{array}$ & 0.6237 \\
\hline$G_{2}$ & $\begin{array}{l}([0.7146,0.7814], \\
[0.3287,0.3916])\end{array}$ & 0.6866 & 0.1205 & $\begin{array}{l}([0.6597,0.7156], \\
[0.3959,0.4465])\end{array}$ & 0.6256 \\
\hline$G_{3}$ & $\begin{array}{l}([0.5706,0.6222], \\
[0.4715,0.5258])\end{array}$ & 0.5441 & 0.1675 & $\begin{array}{l}([0.5360,0.5867], \\
[0.5022,0.5535])\end{array}$ & 0.5149 \\
\hline$G_{4}$ & $\begin{array}{l}([0.6337,0.6875], \\
[0.4024,0.4580])\end{array}$ & 0.6045 & 0.1328 & $\begin{array}{l}([0.6206,0.6737], \\
[0.4164,0.4703])\end{array}$ & 0.5921 \\
\hline$G_{5}$ & $\begin{array}{l}([0.5171,0.5660], \\
[0.5242,0.5771])\end{array}$ & 0.4958 & 0.1613 & $\begin{array}{l}([0.5166,0.5655], \\
[0.5258,0.5787])\end{array}$ & 0.4949 \\
\hline
\end{tabular}


Table 8. Final ranking of green suppliers.

\begin{tabular}{ccccc}
\hline $\begin{array}{c}\text { Green } \\
\text { Suppliers }\end{array}$ & $\begin{array}{c}\text { The } \\
\text { q-RIVOF } \\
\text { Ratio System }\end{array}$ & $\begin{array}{c}\text { The q-RIVOF Reference } \\
\text { Point Approach }\end{array}$ & $\begin{array}{c}\text { The q-RIVOF Full } \\
\text { Multiplicative Form }\end{array}$ & The Final Ranking \\
\hline$G_{1}$ & 2 & 1 & 2 & 2 \\
$G_{2}$ & 1 & 2 & 1 & 1 \\
$G_{3}$ & 4 & 5 & 4 & 4 \\
$G_{4}$ & 3 & 3 & 3 & 5 \\
$G_{5}$ & 5 & 4 & 5 & 5 \\
\hline
\end{tabular}

\subsection{Sensitivity Analysis}

To investigate the robustness of the proposed approach based on the q-RIVOF-MULTIMOORA method, we can implement the decision-making process of the aforementioned numerical example with several groups of criteria weight vectors, as presented in Table 9. Obviously, the Exp.0 represents the weights of criteria obtained in the proposed approach, while each criterion is given a relatively large weight value in other examples, respectively. Subsequently, the different rankings of green suppliers with different weight vectors of criteria are illustrated in Figure 4.

Table 9. Weights of criteria in the sensitivity analysis.

\begin{tabular}{cccccc}
\hline Criteria & Exp.0 & Exp.1 & Exp.2 & Exp.3 & Exp.4 \\
\hline$C_{1}$ & 0.241 & 0.400 & 0.200 & 0.200 & 0.200 \\
$C_{2}$ & 0.223 & 0.200 & 0.400 & 0.200 & 0.200 \\
$C_{3}$ & 0.220 & 0.200 & 0.200 & 0.400 & 0.200 \\
$C_{4}$ & 0.316 & 0.200 & 0.200 & 0.200 & 0.400 \\
\hline
\end{tabular}

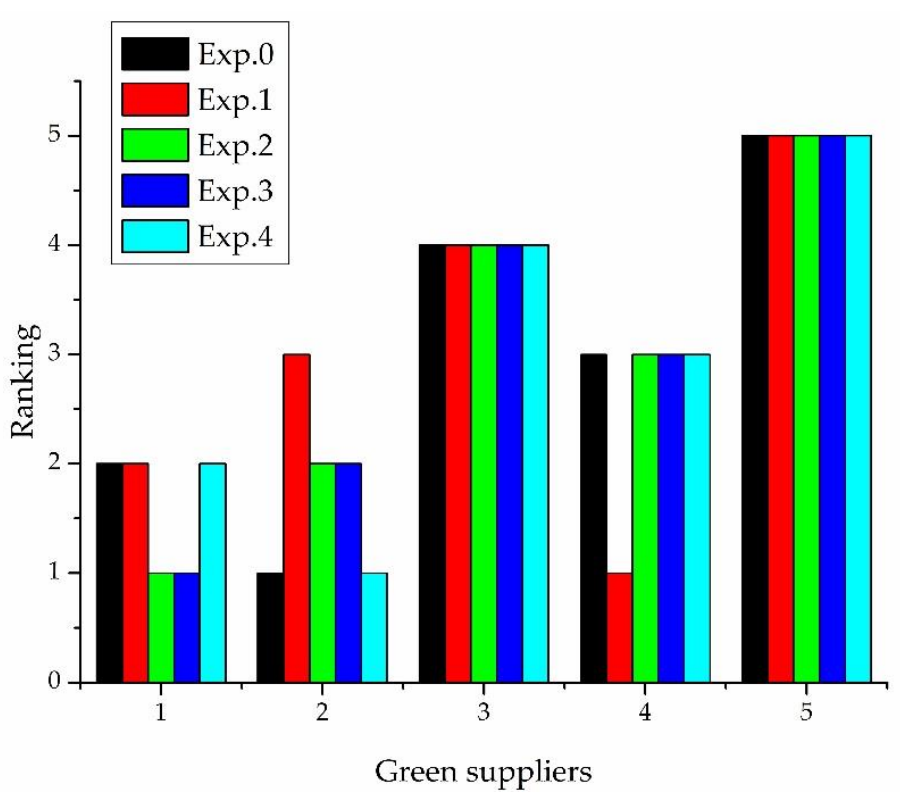

Figure 4. Rankings of sensitivity analysis.

Figure 4 indicates that the ranking order of green supplier $G_{2}$ changes significantly from one to three in the Exp.1, which can be explained by the relatively large weight value of criteria $C_{1}$ and the outstanding evaluation information of green supplier $G_{2}$ concerning criteria $C_{1}$. Besides, in other examples, the ranking orders of different alternatives almost remain unchanged, especially for the green suppliers $G_{3}, G_{4}$, and $G_{5}$. Because of the ranking indexes obtained from the evaluation information of green suppliers $G_{1}$ and $G_{2}$ are very close, their ranking orders have changed slightly in some cases. Thus, the sensitivity analysis result shows that the proposed approach has a relatively strong 
robustness. On the other hand, the weights of criteria are proven to be a key factor during the GSS process, hence we should utilize the appropriate weighting method to calculate the criteria weights in practice. The criteria weights can be computed objectively using the weighting approach based on a weighted entropy measure in the proposed approach, which is a good choice with the information of criteria weights being completely unknown.

\subsection{Discussion}

To further discuss the effectiveness of the proposed approach, several existing GSS methods developed in the literature are applied to carry out the same numerical example above, which include the method based on the q-rung interval-valued orthopair fuzzy weighted Hamy mean (q-RIVOFWHM) operator [23], the method based on the q-rung interval-valued orthopair fuzzy weighted dual Hamy mean (q-RIVOFWDHM) operator [23], and the intuitionistic fuzzy TOPSIS (IF-TOPSIS) based method [17]. It is worth noting that the existing approaches were all developed to solve the GSS issues without a large-scale group of decision makers; thus, twenty decision makers are assumed as equally important during the selection process of the existing approaches. In addition, the subjective weights of criteria in the IF-TOPSIS approach are assumed as $\boldsymbol{w}=(0.300,0.200,0.300,0.200)^{T}$ [23]. The different rankings obtained by the GSS methods are presented in Figure 5 .

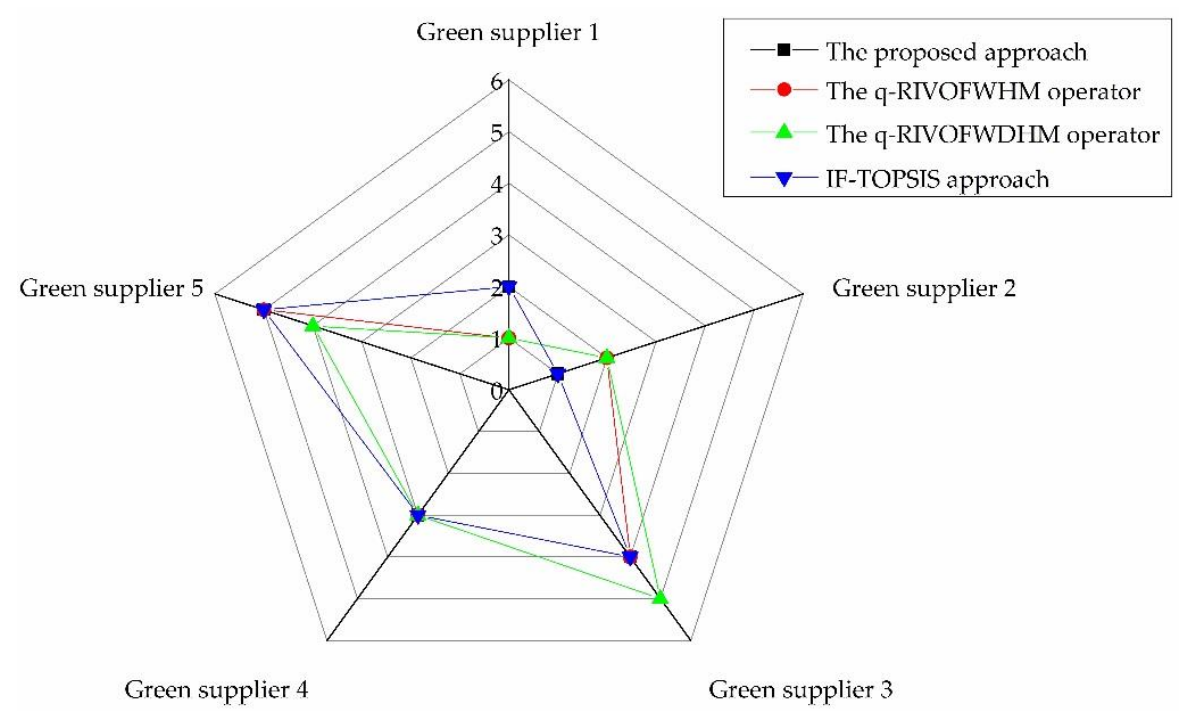

Figure 5. Rankings of different green supplier selection (GSS) approaches.

According to the literature $[10,11]$, the GSS and order allocation issues can be solved by novel multi-objective programming models simultaneously, in which the solution time is an important index to measure the quality of different methods. However, both the proposed approach and the aforementioned existing GSS approaches regard the GSS process as a kind of MCDM issue, thus their solution procedures of the numerical example in this paper are all a scientific numerical calculation process, and the key factor affecting their solution time is the size of original data, which is different from the optimization problems. Combined with the Matlab software, the solution time of different GSS methods taken to obtain the ranking result is all about ten seconds. Obviously, the quality of the proposed approach and the existing GSS approaches cannot be judged according to their solution time; nevertheless, we can analyze the advantages and disadvantages of the proposed method by the ranking results in Figure 5 and the calculation processes of different GSS methods as in the following.

Figure 5 indicates that the ranking obtained by the IF-TOPSIS approach is as same as that of the proposed approach, and the ranking orders of several green suppliers have changed slightly in the methods based on the q-RIVOFWHM and q-RIVOFWDHM operators. These inconsistent ranking results are mainly caused by two reasons: (1) The non-consensus evaluation information that deviates 
from the group evaluation information, i.e., the evaluation information given by decision makers $D M_{11}$, $D M_{14}, D M_{18}$, and $D M_{20}$, may be expressed inevitably when large-scale decision makers participate in the evaluation process. Then, the accuracy of the rankings will be reduced without ignoring or improving the non-consensus opinions in the methods based on the q-RIVOFWHM and q-RIVOFWDHM operators, and (2) compared with the information fusion of the q-RIVOFWHM and q-RIVOFWDHM operators, ranking obtained by the proposed approach is determined according to three rankings of relevant steps in the q-RIVOF-MULTIMOORA method, which may also lead to different ranking results; however, the robustness of ranking is improved in the q-RIVOF-MULTIMOORA approach. Besides, although the ranking of green suppliers remains unchanged in the IF-TOPSIS approach, the GSS approach based on the IF-TOPSIS method still presents several limitations according to its calculation process. Similarly, the non-consensus opinions are not addressed in the IF-TOPSIS approach, which will affect the accuracy of ranking negatively. Furthermore, compared with q-RIVOFNs, the intuitionistic fuzzy numbers are less capable of expressing the fuzziness of evaluation information, and the evaluation freedom of decision makers is limited. However, considering the subjective and objective factors, the weights of criteria are determined comprehensively in the IF-TOPSIS approach, which is more flexible and reasonable than the weighting method in the proposed approach.

Based on the aforementioned analysis, several advantages of utilizing the proposed method to rank green suppliers are summarized as below.

(1) The q-RIVOFNs are introduced to evaluate green suppliers, which can not only represent the positive, negative, and indeterminacy membership levels of decision makers, simultaneously, but also relax the evaluation environment of decision makers. Furthermore, because of three degrees above are expressed by interval numbers, the uncertainty of evaluation information can be characterized effectively.

(2) With the GSS issues becoming more and more complex, the scale of the decision maker team will become bigger and bigger. Considering the situation of large-scale decision makers participating in the evaluation mission, a clustering method with a deletetion mechanism is constructed to aggregate the evaluation information, which can reduce the negative impact of the non-consensus opinions on the ranking of green suppliers.

(3) The q-RIVOFWA operator, the weighted Chebyshev distance of q-RIVOFNs, and the q-RIVOFWG operator are introduced to improve the ratio system, the reference point approach, and the full multiplicative form of MULTIMOORA approach, respectively. Subsequently, the q-RIVOFMULTIMOORA approach is developed to rank green suppliers, in which the weight vector of criteria is highlighted during the ranking process, and the robustness of the ranking result is relatively strong.

Nevertheless, the proposed large-scale GSS method still has several drawbacks. In this paper, the relationship between different criteria is assumed as independent. In contrast, the interaction may exist between different criteria; thus, the proposed approach cannot solve the GSS issues under these situations. The weight vector of criteria is computed by weighted entropy weighting method, in which the subjective factor is ignored in the proposed approach. Furthermore, another important issue in GSCM, i.e., the order allocation $[10,11]$ issue, is not considered in this study.

\section{Conclusions}

With the increasing importance of green suppliers to enterprises, the scale of decision makers is also constantly increasing during the practical GSS procedure. To investigate the large-scale GSS problems, this paper develops a new large-scale GSS approach under a q-RIVOF environment. The q-RIVOFNs are introduced to evaluate green suppliers, in which the uncertainty and fuzziness of evaluation information can be expressed validly, and the range of decision makers' evaluation information is enlarged. Combined with the similarity measure of q-RIVOFNs and the clustering principles, a clustering method is developed to divide the large-scale decision makers into several 
subgroups, while the non-consensus opinions are ignored. Based on the consensus degrees of different subgroups, the weights of subgroups are computed; consequently, the collective evaluation information can be determined by the q-RIVOFWA operator. Next, the weights of criteria are determined using the weighted entropy weighting method. Later, the q-RIVOF-MULTIMOORA approach is constructed to rank green suppliers, in which the q-RIVOF ratio system, the q-RIVOF reference point approach, and the q-RIVOF full multiplicative form are improved by the q-RIVOFWA operator, the weighted Chebyshev distance of q-RIVOFNs, and the q-RIVOFWG operator, respectively. At last, a numerical example is presented to demonstrate the feasibility of the proposed approach. Furthermore, the advantages of utilizing the proposed approach to rank green suppliers are summarized, which include the uncertainty and fuzziness of evaluation information that can be further characterized, the large-scale GSS issue that can be solved effectively by ignoring the non-consensus evaluation information, and the robustness of the ranking result being improved to a certain extent.

In future research, the proposed GSS approach should be revised to solve the GSS issues that interactions or dependencies exist among the criteria, and the weight vector of criteria should be determined by considering the subjective and objective aspects of weight information. Furthermore, inspired by the literature $[10,11]$, we should integrate the order allocation process into the proposed approach to implement the GSCM procedure more effectively.

Author Contributions: Concept of this paper, B.S.; methodology, L.L.; writing-original draft preparation, L.L. and W.C.; writing — review and editing, W.C. and B.S.; funding acquisition, L.L., B.S. and M.T.

Funding: This work was supported by The Ministry of Education of Humanities and Social Science Project (Grant No. 14YJCZH099); the Hunan Provincial Philosophy and Social Science Project (Grant No. 12YBB145); and the Hunan Provincial Social Science Achievement Appraisal Committee Project (Grant No. XSP18YBC146).

Conflicts of Interest: The authors declare no conflict of interest.

\section{References}

1. Rostamzadeh, R.; Govindan, K.; Esmaeili, A.; Sabaghi, M. Application of fuzzy VIKOR for evaluation of green supply chain management practices. Ecol. Indic. 2015, 49, 188-203. [CrossRef]

2. Sahu, N.K.; Datta, S.; Mahapatra, S.S. Establishing green supplier appraisement platform using grey concepts. Grey Syst. 2012, 2, 395-418. [CrossRef]

3. Vachon, S. Green supply chain practices and the selection of environmental technologies. Int. J. Prod. Res. 2007, 45, 4357-4379. [CrossRef]

4. Cabral, I.; Grilo, A.; Cruz-Machado, V. A decision-making model for lean, agile, resilient and green supply chain management. Int. J. Prod. Res. 2012, 50, 4830-4845. [CrossRef]

5. Beamon, B.M. Designing the green supply chain. Logist. Inf. Manag. 2013, 12, 332-342. [CrossRef]

6. Bai, C.; Sarkis, J. Green supplier development: Analytical evaluation using rough set theory. J. Clean. Prod. 2010, 18, 1200-1210. [CrossRef]

7. Kannan, D.; Govindan, K.; Rajendran, S. Fuzzy axiomatic design approach based green supplier selection: A case study from Singapore. J. Clean. Prod. 2015, 96, 194-208. [CrossRef]

8. Blome, C.; Hollos, D.; Paulraj, A. Green procurement and green supplier development: Antecedents and effects on supplier performance. Int. J. Prod. Res. 2014, 52, 32-49. [CrossRef]

9. Govindan, K.; Rajendran, S.; Sarkis, J.; Murugesan, P. Multi criteria decision making approaches for green supplier evaluation and selection: A literature review. J. Clean. Prod. 2015, 98, 66-83. [CrossRef]

10. Moheb-Alizadeh, H.; Handfield, R. Sustainable supplier selection and order allocation: A novel multi-objective programming model with a hybrid solution approach. Comput. Ind. Eng. 2019, 129, 192-209. [CrossRef]

11. Moheb-Alizadeh, H.; Handfield, R. An integrated chance-constrained stochastic model for efficient and sustainable supplier selection and order allocation. Int. J. Prod. Res. 2018, 56, 6890-6916. [CrossRef]

12. Qin, J.; Liu, X.; Pedrycz, W. An extended TODIM multi-criteria group decision making method for green supplier selection in interval type-2 fuzzy environment. Eur. J. Oper. Res. 2017, 258, 626-638. [CrossRef]

13. Zhu, J.; Li, Y.; Rosen, M.A. Green supplier selection based on consensus process and integrating prioritized operator and Choquet integral. Sustainability 2018, 10, 2744. [CrossRef] 
14. Wang, J.; Wei, G.W.; Wei, Y. Models for green supplier selection with some 2-tuple linguistic neutrosophic number Bonferroni mean operators. Symmetry 2018, 10, 131. [CrossRef]

15. Banaeian, N.; Mobli, H.; Fahimnia, B.; Nielsen, I.E.; Omid, M. Green supplier selection using fuzzy group decision making methods: A case study from the agri-food industry. Comput. Oper. Res. 2018, 89, 337-347. [CrossRef]

16. Ghorabaee, M.K.; Zavadskas, E.K.; Amiri, M.; Esmaeili, A. Multi-criteria evaluation of green suppliers using an extended WASPAS method with interval type-2 fuzzy sets. J. Clean. Prod. 2016, 137, 213-229. [CrossRef]

17. Cao, Q.; Wu, J.; Liang, C. An intuitionsitic fuzzy judgement matrix and TOPSIS integrated multi-criteria decision making method for green supplier selection. J. Intell. Fuzzy Syst. 2015, 28, 117-126.

18. Yager, R.R. Generalized orthopair fuzzy sets. IEEE Trans. Fuzzy Syst. 2017, 25, 1222-1230. [CrossRef]

19. Wang, R.; Li, Y. A novel approach for green supplier selection under a q-rung orthopair fuzzy environment. Symmetry 2018, 10, 687. [CrossRef]

20. Liu, P.; Liu, J. Some q-rung orthopair fuzzy Bonferroni mean operators and their application to multi-attribute group decision making. Int. J. Intell. Syst. 2018, 33, 315-347. [CrossRef]

21. Wei, G.; Gao, H.; Wei, Y. Some q-rung orthopair fuzzy Heronian mean operators in multiple attribute decision making. Int. J. Intell. Syst. 2018, 33, 1426-1458. [CrossRef]

22. Joshi, B.P.; Singh, A.; Bhatt, P.K.; Vaisla, K.S. Interval valued q-rung orthopair fuzzy sets and their properties. J. Intell. Fuzzy Syst. 2018, 35, 5225-5230. [CrossRef]

23. Wang, J.; Gao, H.; Wei, G.; Wei, Y. Methods for multiple-attribute group decision making with q-rung interval-valued orthopair fuzzy information and their applications to the selection of green suppliers. Symmetry 2019, 11, 56. [CrossRef]

24. Liu, H.C.; You, X.Y.; Tsung, F.; Ji, P. An improved approach for failure mode and effect analysis involving large group of experts: An application to the healthcare field. Qual. Eng. 2018, 30, 762-775. [CrossRef]

25. Xu, X.H.; Du, Z.J.; Chen, X.H. Consensus model for multi-criteria large-group emergency decision making considering non-cooperative behaviors and minority opinions. Decis. Support Syst. 2015, 79, 150-160. [CrossRef]

26. $\mathrm{Wu}, \mathrm{Z}$; $\mathrm{Xu}, \mathrm{J}$. A consensus model for large-scale group decision making with hesitant fuzzy information and changeable clusters. Inf. Fusion 2018, 41, 217-231. [CrossRef]

27. Brauers, W.K.M. Project management for a country with multiple objectives. Czech Econ. Rev. 2012, 6, 80-101.

28. Brauers, W.K.M.; Zavadskas, E.K. Project management by MULTIMOORA as an instrument for transition economies. Technol. Econ. Dev. Econ. 2010, 16, 5-24. [CrossRef]

29. Li, Y.L.; Wang, R.; Chin, K.S. New failure mode and effect analysis approach considering consensus under interval-valued intuitionistic fuzzy environment. Soft Comput. 2019. [CrossRef]

30. Zhao, H.; You, J.X.; Liu, H.C. Failure mode and effect analysis using MULTIMOORA method with continuous weighted entropy under interval-valued intuitionistic fuzzy environment. Soft Comput. 2017, 21, 5355-5367. [CrossRef]

31. Baležentis, T.; Baležentis, A. A survey on development and applications of the multi-criteria decision making method MULTIMOORA. J. Multi-Criteria Decis. Anal. 2014, 21, 209-222.

32. Deshmukh, S.; Sunnapwar, V. Fuzzy analytic hierarchy process (FAHP) for green supplier selection in Indian industries. In Proceedings of the International Conference on Intelligent Manufacturing and Automation, Tokyo, Japan, 27-30 September 2019; Springer: Singapore, 2019; pp. 679-687.

33. Dobos, I.; Vörösmarty, G. Evaluating green suppliers: Improving supplier performance with DEA in the presence of incomplete data. Cent. Eur. J. Oper. Res. 2019, 27, 483-495. [CrossRef]

34. Dobos, I.; Vörösmarty, G. Inventory-related costs in green supplier selection problems with data envelopment analysis (DEA). Int. J. Prod. Econ. 2019, 209, 374-380. [CrossRef]

35. Govindan, K.; Kadziński, M.; Sivakumar, R. Application of a novel PROMETHEE-based method for construction of a group compromise ranking to prioritization of green suppliers in food supply chain. Omega 2016, 71, 129-145. [CrossRef]

36. Matić, B.; Jovanović, S.; Das, D.K.; Zavadskas, E.K.; Stević, Ž.; Sremac, S.; Marinković, M. A new hybrid MCDM model: Sustainable supplier selection in a construction company. Symmetry 2019, 11, 353. [CrossRef]

37. Liu, H.C.; Quan, M.Y.; Li, Z.; Wang, Z.L. A new integrated MCDM model for sustainable supplier selection under interval-valued intuitionistic uncertain linguistic environment. Inf. Sci. 2019, 486, 254-270. [CrossRef] 
38. Yucesan, M.; Mete, S.; Serin, F.; Celik, E.; Gul, M. An integrated best-worst and interval type-2 fuzzy TOPSIS methodology for green supplier selection. Mathematics 2019, 7, 182. [CrossRef]

39. Tsui, C.W.; Wen, U.P. A hybrid multiple criteria group decision-making approach for green supplier selection in the TFT-LCD industry. Math. Probl. Eng. 2014, 2014, 709872. [CrossRef]

40. Abdel-Baset, M.; Chang, V.; Gamal, A.; Smarandache, F. An integrated neutrosophic ANP and VIKOR method for achieving sustainable supplier selection: A case study in importing field. Comput. Ind. 2019, 106, 94-110. [CrossRef]

41. Hashemi, S.H.; Karimi, A.; Tavana, M. An integrated green supplier selection approach with analytic network process and improved grey relational analysis. Int. J. Prod. Econ. 2015, 159, 178-191. [CrossRef]

42. Kuo, T.C.; Hsu, C.W.; Li, J.Y. Developing a green supplier selection model by using the DANP with VIKOR. Sustainability 2015, 7, 1661-1689. [CrossRef]

43. Liang, Y.; Liu, J.; Qin, J.; Tu, Y. An improved multi-granularity interval 2-tuple TODIM approach and its application to green supplier selection. Int. J. Fuzzy Syst. 2019, 21, 129-144. [CrossRef]

44. Rashidi, K.; Cullinane, K. A comparison of fuzzy DEA and fuzzy TOPSIS in sustainable supplier selection: Implications for sourcing strategy. Expert Syst. Appl. 2019, 121, 266-281. [CrossRef]

45. Zadeh, L.A. Fuzzy sets. Inf. Control 1965, 8, 338-353. [CrossRef]

46. Zhou, X.; Pedrycz, W.; Kuang, Y.; Zhang, Z. Type-2 fuzzy multi-objective DEA model: An application to sustainable supplier evaluation. Appl. Soft Comput. 2016, 46, 424-440. [CrossRef]

47. Atanassov, K.T. Intuitionistic fuzzy sets. Fuzzy Sets Syst. 1986, 20, 87-96. [CrossRef]

48. Atanassov, K.T. Interval valued intuitionistic fuzzy sets. In Intuitionistic Fuzzy Sets; Publisher Name Physica: Heidelberg, Germany, 1999; pp. 139-177.

49. Yager, R.R. Pythagorean membership grades in multicriteria decision making. IEEE Trans. Fuzzy Syst. 2013, 22, 958-965. [CrossRef]

50. Peng, X.; Yang, Y. Fundamental properties of interval-valued Pythagorean fuzzy aggregation operators. Int. J. Intell. Syst. 2016, 31, 444-487. [CrossRef]

51. Zhang, Z.; Guo, C.; Martínez, L. Managing multigranular linguistic distribution assessments in large-scale multiattribute group decision making. IEEE Trans. Syst. ManCybern. Syst. 2016, 47, 3063-3076. [CrossRef]

52. Palomares, I.; Martinez, L.; Herrera, F. A consensus model to detect and manage noncooperative behaviors in large-scale group decision making. IEEE Trans. Fuzzy Syst. 2013, 22, 516-530. [CrossRef]

53. Liu, Y.; Fan, Z.P.; Zhang, X. A method for large group decision-making based on evaluation information provided by participators from multiple groups. Inf. Fusion 2016, 29, 132-141. [CrossRef]

54. Labella, Á.; Liu, Y.; Rodríguez, R.M.; Martínez, L. Analyzing the performance of classical consensus models in large scale group decision making: A comparative study. Appl. Soft Comput. 2018, 67, 677-690. [CrossRef]

55. Du, W.S. Minkowski-type distance measures for generalized orthopair fuzzy sets. Int. J. Intell. Syst. 2018, 33, 802-817. [CrossRef]

56. Du, Y.; Hou, F.; Zafar, W.; Yu, Q.; Zhai, Y. A novel method for multiattribute decision making with interval-valued Pythagorean fuzzy linguistic information. Int. J. Intell. Syst. 2017, 32, 1085-1112. [CrossRef]

57. Liu, B.; Shen, Y.; Zhang, W.; Chen, X.; Wang, X. An interval-valued intuitionistic fuzzy principal component analysis model-based method for complex multi-attribute large-group decision-making. Eur. J. Oper. Res. 2015, 245, 209-225. [CrossRef]

58. Zhou, S.; Xu, X.; Zhou, Y.; Chen, X. A large group decision-making method based on fuzzy preference relation. Int. J. Inf. Technol. Decis. Mak. 2017, 16, 881-897. [CrossRef]

59. Xu, X.H.; Zhong, X.Y.; Chen, X.H.; Zhou, Y.J. A dynamical consensus method based on exit-delegation mechanism for large group emergency decision making. Knowl.-Based Syst. 2015, 86, 237-249. [CrossRef]

60. Zhu, J.; Zhang, S.; Chen, Y.; Zhang, L. A hierarchical clustering approach based on three-dimensional gray relational analysis for clustering a large group of decision makers with double information. Group Decis. Negot. 2016, 25, 325-354. [CrossRef]

61. Cai, C.G.; Xu, X.H.; Wang, P.; Chen, X.H. A multi-stage conflict style large group emergency decision-making method. Soft Comput. 2017, 21, 5765-5778. [CrossRef]

62. Fishburn, P.C.; Gehrlein, W.V. Borda's rule, positional voting, and condorcet's simple majority principle. Public Choice 1976, 28, 79-88. [CrossRef]

63. Alonso, S.; Herrera-Viedma, E.; Chiclana, F.; Herrera, F. A web based consensus support system for group decision making problems and incomplete preferences. Inf. Sci. 2010, 180, 4477-4495. [CrossRef] 
64. Chiclana, F.; Mata, F.; Martínez, L.; Herrera-Viedma, E.; Alonso, S. Integration of a consistency control module within a consensus model. Int. J. Uncertain. Fuzziness Knowl.-Based Syst. 2008, 16, 35-53. [CrossRef]

65. Zhang, H.Y.; Ji, P.; Wang, J.Q.; Chen, X.H. An improved weighted correlation coefficient based on integrated weight for interval neutrosophic sets and its application in multi-criteria decision-making problems. Int. J. Comput. Intell. Syst. 2015, 8, 1027-1043. [CrossRef]

66. Zhang, X.; Jin, F.; Liu, P. A grey relational projection method for multi-attribute decision making based on intuitionistic trapezoidal fuzzy number. Appl. Math. Model. 2013, 37, 3467-3477. [CrossRef]

C 2019 by the authors. Licensee MDPI, Basel, Switzerland. This article is an open access article distributed under the terms and conditions of the Creative Commons Attribution (CC BY) license (http://creativecommons.org/licenses/by/4.0/). 